\title{
Fundamental aspects of electrochemically controlled wetting of nanoscale composite materials
}

\author{
A. Robert Hillman*a, Karl S. Ryder ${ }^{\mathrm{a}}$, Hani K. Ismail ${ }^{\mathrm{a}, \mathrm{b}}$, Asuman Unal ${ }^{\mathrm{a}}$ and Annelies \\ Voorhaar $^{\mathrm{a}}$ \\ ${ }^{a}$ Materials Centre, Department of Chemistry, University of Leicester, Leicester LE1 \\ $7 R H$ \\ ${ }^{\mathrm{b}}$ Chemistry Department, University of Koya, Erbil, Iraq
}

Electroactive films based on conducting polymers have numerous potential applications, but practical devices frequently require a combination of properties not met by a single component. This has prompted extension to composite materials, notably those in which particulates are immobilised within a polymer film. Irrespective of the polymer and the intended application, film wetting is important: by various means, it facilitates transport processes - of electronic charge, charge-balancing counter ions ("dopant") and analyte/reactant molecules - and motion of polymer segments. While film solvent content and transfer have been widely studied for pristine polymer films exposed to molecular solvents, extension to non-conventional solvents (such as ionic liquids) or to composite films has been given much less attention. Here we consider such cases, based on polyaniline films. We explore two factors: the nature of the electrolyte (solvent and filmpermeating ions) and the effect of introducing particulate species into the film. In the first instance, we compare film behaviours when exposed to a conventional protic solvent (water) with an aprotic ionic liquid (Ethaline) and the intermediate case of a protic ionic liquid (Oxaline). Secondly, we explore the effect of inclusion of physically diverse particulates: multi-walled carbon nanotubes, graphite or molybdenum dioxide. We use electrochemistry to control and monitor film redox state and change therein, and acoustic wave measurements to diagnose rheologically vs. gravimetrically determined response. The outcomes provide insights of relevance to future practical applications, including charge/discharge rates and cycle life for energy storage devices, "salt" transfer in water purification technologies, and the extent of film "memory" of previous environment when sequentially exposed to different media.

Keywords: Conducting polymer; electroactive film; composite; solvation; ionic liquid

* Email: $\underline{\operatorname{arh} 7 @ 1 e . a c . u k}$ 


\section{INTRODUCTION}

Conducting polymers based on aromatic monomers have attracted huge research interest ${ }^{1}$ : examples include polypyrrole ${ }^{2}$; polyaniline ${ }^{3}$ and derivatives such as poly-o-toluidine and poly-o-aminophenol; polythiophene $e^{4-6}$ and its derivative poly $(3,4-$

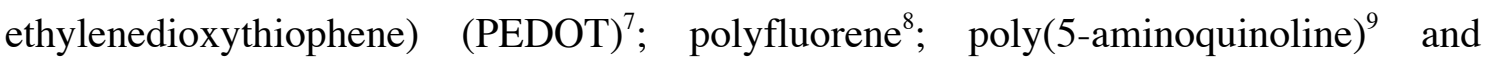
poly[bis(phenylamino)disulphide $]^{10}$. As a result of their switchable electronic, optical, chemical and mechanical characteristics, these materials have potential applications in sensors $^{11-14}$, electrochromic devices ${ }^{11}$, corrosion protection ${ }^{15-19}$, energy storage $^{11,20}$ (including supercapacitors ${ }^{21}$ ) and artificial muscles ${ }^{22,23}$. Inevitably, such applications require combinations of properties that are not generally found in a single material, so it is natural to move to composites. Additionally, it has become widely recognized that dynamics within such systems - from transport rates of charge balancing ions and analyte species to the nanomechanical motions of the polymer chains - are governed by the solvent content, i.e. the internal wettability of the material. In this study, we bring these two aspects together by exploring solvation phenomena for polyaniline composites containing multi-walled carbon nanotubes (MWCNTs), molybdenum dioxide and/or graphite when exposed to aqueous and room temperature ionic liquid media.

Polyaromatic conducting polymers, typified by polyaniline, may be interconverted between their insulating and conducting forms by electrochemically controllable redox processes $^{1,24}$. Electron transfer at the electrode/polymer interface creates positive charge sites, for which electroneutrality requires the entry of anions (or exit of cations) at the polymer/solution interface ${ }^{25}$ (colloquially, “(un-)doping”). These ion transfers have been explored in detail for polypyrrole exposed to aqueous ${ }^{26-31}$ and non-aqueous $\mathrm{s}^{32-34}$ media. When the anion and cation are of very different size (and mobility), the dominant ion transfer may also be time-dependent ${ }^{35,36}$; this is most obviously the case when the cation is proton (as for polyaniline ${ }^{37}$ ). The consequent dramatic changes in film lyophilicity drive solvent transfers into/out of the film ${ }^{38-40}$. Formally these can be expressed in terms of thermodynamic activity coefficients ${ }^{41,42}$, but quantitative predictions are not generally possible, so one must resort to experimental observations ${ }^{43,44}$. When the transferred ion is proton, this can significantly influence the extent of solvent transfer ${ }^{45}$.

Polyaniline may be prepared by chemical ${ }^{21,46}$ and electrochemical ${ }^{46}$ means; when film formation on an electrode is required, the latter is more effective ${ }^{21,47}$. Most commonly 
this is accomplished from acidic aqueous media, although deposition from neutral solution $^{48}$ and from ionic liquids ${ }^{49}$ have been described. The process and the characteristics of the resultant film are influenced by the counter ion $^{50-52}$, the electrode material $^{53}$ and the electrolyte composition ${ }^{54-56}$.

Polyaniline is slightly unusual amongst conducting polymers in that it has three readily accessible redox states ${ }^{57}$ : leucoemeraldine (the fully reduced form, with all nitrogen atoms as amine groups, -NH-), emeraldine (the half-oxidized form, with equal amounts of amine and imine groups) and pernigraniline (the fully oxidized form, with all the nitrogen atoms as imine groups, $=\mathrm{NH}-)^{47,58}$. A complication is that the last form is unstable at high anodic potentials in aqueous media and degrades to benzoquinone and various oligomers. This places a constraint on the positive potential used to deposit the polymer. Failure to control this leads to loss of electroactive sites, manifested as a broadening and gradual diminution of the redox peaks seen in cyclic voltammograms. The effect may also be mitigated to some extent by choice of the anion present. ${ }^{52}$

Manipulation of polyaniline film properties to suit a particular application may be effected by changing film composition - through the formation of copolymers ${ }^{59-61}$ or the inclusion of particulates ${ }^{62-64}$ - or by a change in electrolyte composition. Inclusion of carbon nanotubes in polyaniline enhances conductivity and charging behaviour ${ }^{65-67}$ and performance in sensing applications ${ }^{68-70}$ and artificial muscles ${ }^{23}$. The carbon nanotubes may act not only as a mechanical component but also as a dopant ${ }^{71,72}$. Homogeneous distribution of the carbon nanotubes is important ${ }^{67,73}$ and may be promoted by direct mixing ${ }^{74}$, surface modification of the carbon ${ }^{71,75-78}$, or use of a third component ${ }^{79}$.

Moving to consideration of the ambient medium, ionic liquids (ILs) are a new class of solvent media consisting of a mixture of organic cations and anions ${ }^{80}$ such that the melting point is below $100^{\circ} \mathrm{C}$; since their melting points are commonly below room temperature ${ }^{81}$ they are often termed room temperature ionic liquids (RTILs). Their unusual and attractive physical properties have prompted exploitation in "green" applications ${ }^{82}$, charge storage systems (batteries and capacitors ${ }^{83,84}$ ) and the fabrication of conducting polymers $^{85-87}$, such as polypyrrole ${ }^{88-90}$, polythiophene ${ }^{91}$, and polyaniline ${ }^{81,92-96}$; in the latter instance, access to higher potentials without degradation ${ }^{97}$ and electroactivity at low proton activity ${ }^{49}$ are particularly relevant. The deep eutectic solvents (DES) we consider 
here are a class of ionic liquids ${ }^{98}$ generated by mixing ammonium salts (e.g., choline chloride, $\mathrm{ChCl}$ ) and neutral organic hydrogen bond donors (e.g., acids, amides, amines and carboxylic acids) $)^{99,100}$. These media have been explored for the deposition of electroactive polymer films such as polyaniline ${ }^{101}$, polypyrrole ${ }^{102}$ and PEDOT $^{7,103}$.

The overarching fundamental aim of the present study is an understanding of how changing electroactive film composition and electrolyte type influences the internal wettability of the film. Specifically, we wish to determine the effects of inclusion of MWCNTs, graphite and/or $\mathrm{MoO}_{2}$ particulates into polyaniline influences the ease of film deposition, subsequent redox dynamics and stability. We wish to determine how these characteristics vary when the films are deposited from, exposed to, and transferred between a conventional aqueous medium and a DES.

The methodology adopted is based on use of an electrochemical control function to dictate the energetics of the system, with determination of the overall rates of film deposition and ion transfer (into/out of the resulting film) from the current response. By using electrodes mounted on an acoustic resonator, we use the associated resonator frequency response either to monitor film mass changes (in the acoustically thin film, i.e. gravimetric, regime) or to identify viscoelastic phenomena (in the acoustically thick film, i.e. viscoelastic, regime). In gravimetric mode, the EQCM has been widely used to study redox-driven ion and solvent transfers ${ }^{43,44,104}$ and polymer dynamics ${ }^{105}$ of electroactive polymer films. Full consideration of the acoustic resonator frequency response is diagnostic of gravimetric or rheological control of the acoustic resonator response ${ }^{105,106}$. From an experimental perspective, this is largely determined by temperature and film solvation ${ }^{105}$, of which the latter is central to the work described here. Since choice of deposition time and/or physical conditions can generate polyaniline films that span both regimes ${ }^{104,105}$, this provides useful insight into the possible role of particulates as mechanically "stiffening" components.

\section{EXPERIMENTAL}

Chemicals and Materials. Aniline (99\%), multi-walled carbon nanotubes (MWCNTs), choline chloride (98\%), oxalic acid dihydrate (Ox) $(\geq 98 \%)$ and ethylene glycol (Eg) (99.8\%) (all from Sigma-Aldrich) were used as supplied. $\mathrm{H}_{2} \mathrm{SO}_{4}(99.9 \%)$ and $\mathrm{HNO}_{3}$ (99.9\%) (both Fisher-Scientific) were used as received. MWCNTs (98\%; Sigma-Aldrich) were functionalised to improve film incorporation (see below). The MWCNTs had 
outside and inside diameters of $10( \pm 1) \mathrm{nm}$ and $4.5( \pm 0.5) \mathrm{nm}$, respectively, and lengths of 3-6 $\mu \mathrm{m}$. Graphite (Gr) (99\%; Alfa Aesar) and molybdenum dioxide (99\%; SigmaAldrich) were used as received. The ranges of particle size were 2-12 $\mu \mathrm{m}$ for graphite and 1-20 $\mu \mathrm{m}$ (typically $15 \mu \mathrm{m}$ ) for $\mathrm{MoO}_{2}$.

Instrumentation. All electrochemical experiments were carried out in a conventional three-electrode system in a locally constructed Teflon cell. For experiments in aqueous medium, a platinum flag (surface area $2 \mathrm{~cm}^{2}$ ) was used as the counter electrode and a $\mathrm{Ag} / \mathrm{AgCl}$ electrode as the reference electrode. In the case of Ethaline, an $\mathrm{Ag}$ wire electrode was used as a (pseudo-)reference electrode. Dependent on the medium, two working electrode materials were used: $\mathrm{Au}$ in aqueous media and Pt in Ethaline and Oxaline (to avoid the problem of Au dissolution in chloride media). The Au working electrode in each case was one of the electrodes on a $10 \mathrm{MHz}$ AT-cut quartz crystal resonator (International Crystal Manufacturing Co. Ltd., Oklahoma City, OK). The electrochemical and piezoelectric active areas were $0.23 \mathrm{~cm}^{2}$ and $0.21 \mathrm{~cm}^{2}$, respectively. In the assembled cell, one of the Au electrodes was exposed to the solution whilst the other was exposed to air. Three configurations of Pt electrode were used: on a quartz crystal resonator (as for $\mathrm{Au}$ ), a disc $\left(1 \mathrm{~mm}\right.$ diameter) or a flag (area $\left.0.55 \mathrm{~cm}^{2}\right)$; see individual figure legends.

The EQCM instrumentation has been described elsewhere ${ }^{104,107}$. Electrochemical data were acquired using an Autolab PGSTAT12 potentiostat (Ecochemie, Holland; controlled with GPES2 software). All QCM measurements were made in the vicinity of the fundamental mode $\left(f_{0}=10 \mathrm{MHz}\right)$ using a Hewlett Packard HP8751A network analyser, connected by a $50 \Omega$ coaxial cable.

Procedures. MWCNTs were functionalised by treatment with concentration nitric acid (300 $\mathrm{mL}$ added to $2 \mathrm{~g}$ of MWCNT powder); the mixture was refluxed for 36 hours at $120^{\circ} \mathrm{C}{ }^{108}$ Ethaline solvents were prepared by mixing ethylene glycol $(\mathrm{Eg})$ and choline chloride $(\mathrm{ChCl})$ at $60^{\circ} \mathrm{C}$ in 2:1 ratio for ETH200 and 4:1 ratio for ETH400 ${ }^{109}$.

Monomer solutions in aqueous medium were prepared from aniline $(0.1-1.0 \mathrm{M})$ and $\mathrm{H}_{2} \mathrm{SO}_{4}(0.1-1.0 \mathrm{M})$ in the presence of various concentrations of MWCNTs $(0.1-20$ $\mathrm{wt} \%$ ); see figure legends for individual cases. Before use in electrochemical deposition, 
each solution was sonicated for one hour. The deposition of polyaniline (PANI) and PANI/MWCNT films was studied both potentiostatically and potentiodynamically, with film coverage varied via potential, potential scan rate and number of deposition cycles (see figure legends). After deposition of the required amount of material, the electrode was disconnected, removed from monomer solution, rinsed and transferred to monomerfree background electrolyte for characterization.

Potentiodynamic electrochemical deposition of PANI and PANI/MWCNT from ETH200 / $1 \mathrm{M}$ aniline / $1 \mathrm{M} \mathrm{H}_{2} \mathrm{SO}_{4}$ in the absence/presence of MWCNTs (10 wt\%) involved 100 cycles at a scan rate $v=100 \mathrm{mV} \mathrm{s}^{-1}$ with 100 cycles. Potentiostatic electrodeposition of PANI and PANI/MWCNT from ETH400 / $1 \mathrm{M}$ aniline / $0.5 \mathrm{M} \mathrm{H}_{2} \mathrm{SO}_{4}$ was carried out, with varying concentrations of MWCNTs $(0,4,8,12,16$ and $20 \mathrm{wt} \%)$. In both instances, the resulting films were transferred to monomer-free $1 \mathrm{M} \mathrm{H}_{2} \mathrm{SO}_{4} / \mathrm{ETH} 200$ or ETH200 for characterization. All film deposition and characterization experiments were carried out at room temperature $\left(20( \pm 2)^{\circ} \mathrm{C}\right)$, except where noted in the figure legend.

The PANI/Gr, $\mathrm{PANI} / \mathrm{MoO}_{2}$ and $\mathrm{PANI} / \mathrm{MoO}_{2} / \mathrm{Gr}$-modified electrodes were prepared from aqueous and $\mathrm{Oxaline}(\mathrm{Ox}: \mathrm{ChCl}=1: 1)$ electrolytes through a stepwise method, as shown in Figure 1. For PANI deposition from Oxaline, the first step was deposition of a thin layer of PANI on Pt from 0.2 M aniline / Oxaline, using 5 potentiodynamic scans ( 0.0 to $1.2 \mathrm{~V} v s$ Ag wire, $\left.v=5 \mathrm{mV} \mathrm{s}^{-1}\right)$. Secondly, the deposition solution was removed from the cell, then ca. $3 \mathrm{mg}$ of $\mathrm{MoO}_{2}, \mathrm{Gr}$ or $\mathrm{Gr}+\mathrm{MoO}_{2}$ (3:1) particles (according to the required composite) were dispersed on the PANI surface and the electrode held at $50^{\circ} \mathrm{C}$ for $24 \mathrm{~h}$. In the third step, further PANI was electrodeposited using the same deposition solution (10 cycles, -0.2 to $1.3 \mathrm{~V}$ vs Ag wire, $v=5 \mathrm{mV} \mathrm{s}^{-1}$ ). The same strategy described above was used for PANI-modified electrodes prepared from aqueous $0.2 \mathrm{M}$ aniline / $1 \mathrm{M} \mathrm{H}_{2} \mathrm{SO}_{4}$ solution, but with a potential range -0.25 to $0.8 \mathrm{~V}$ versus $\mathrm{Ag} / \mathrm{AgCl}$. In the first stage, one potential cycle was used and in the last step five cycles were used (all at $v=5 \mathrm{mV} \mathrm{s}^{-1}$ ). After polymerisation, each PANI composite modified electrode was cycled (100 cycles; $v=5 \mathrm{mV} \mathrm{s}^{-1}$ ) in different monomer-free solutions: Ethaline (2Eg: $\left.\mathrm{ChCl}\right), 0.5 \mathrm{M} \mathrm{H}_{2} \mathrm{SO}_{4}$, and Ethaline, sequentially, for films grown from Oxaline; and $0.5 \mathrm{M} \mathrm{H}_{2} \mathrm{SO}_{4}$, Ethaline and $0.5 \mathrm{M} \mathrm{H}_{2} \mathrm{SO}_{4}$, sequentially for films grown from $1 \mathrm{M} \mathrm{H}_{2} \mathrm{SO}_{4}$ aqueous solution. 


\section{RESULTS AND DISCUSSION}

\section{Electrodeposition of PANI and PANI/MWCNT from aqueous medium}

We first compare the depositions of PANI (see Figure 2) and PANI/MWCNT (Figure 3) films from aqueous media. Panels a show the $i$ - $E$ curves for potentiodynamic deposition over the course of 10 cycles at $v=10 \mathrm{mV} \mathrm{s}^{-1}$. The experiment of Figure 2 is the "control" experiment: the data are entirely typical of what has been reported by many authors, for example the presence of a so-called nucleation loop during the first cycle (see black trace in the range 0.9-1.1 V in Figure 2a) and the steady increase of anodic and cathodic peaks at lower potentials, as polymer is progressively deposited on the surface. In the presence of MWCNTs (see Figure 3a) the picture is qualitatively similar, but the reversible peaks (in the range 0.2-0.8 V) are larger and somewhat broader, consistent with more rapid deposition of polymer on the surface. The charge (Q) vs E plots in panels b provide progressive coulometric assay of film deposition. Comparison of the cathodic charge involved in (reversible) reduction of the film and the integrated (irreversible) charge consumed in deposition of the film yields ratios of 0.26 and 0.46 , respectively, for PANI and PANI/MWCNT systems. Quantitative deposition and full reduction across both redox processes is associated with a ratio of 0.5 ; we deduce that the efficiency of PANI/MWCNT deposition is high.

Simplistically, QCM frequency response data might also be expected to provide corresponding mass changes during film deposition. However, before interpreting these data it is necessary to diagnose whether this response is gravimetrically or viscoelastically controlled. Full frequency response curves in the vicinity of the fundamental resonance $\left(f_{0} \approx 10 \mathrm{MHz}\right.$ ) before and at the end of the full set of deposition cycles of the experiments in Figures 2 and 3 undoubtedly show some decrease in admittance, but not the dramatic peak diminution and broadening characteristic of viscoelastic films. We therefore deduce that interpretation of the resonant frequency in gravimetric terms (using the Sauerbrey equation) is a good approximation. This argument is supported by the fact that the curvature in the (perceived) mass change $v s$ charge plots is modest, i.e. calculation of molar mass changes for thin films does not lead to radically different conclusions to those at the end of deposition. On this basis, film mass changes as a function of potential are shown in panels c of Figures 2 and 3. 
Qualitatively, the progressive "drift" towards increasing mass as polymer is generated and accumulated on the surface at the anodic end of each cycle is entirely as one would expect. However, the striking feature is that the mass changes for film deposition of the pure polymer film are much larger than those for the polymer composite, despite the fact that the charge passed (see panels c) is significantly smaller. The alternating increases and decreases in mass below the threshold for polymerization are associated with redoxdriven ion (and solvent; see below) transfers into/out of film deposited on previous cycles.

This is made more obvious by comparing the mass and charge changes directly (see panels d of Figures 2 and 3). Expressed simplistically, smaller amounts of charge generate larger amounts of film in the case of the pure polymer. The issue here is that "film" is not necessarily synonymous with "polymer", since the film may contain solvent and, in the latter case, MWCNTs. There is some curvature to both the mass vs charge plots, which we attribute to (modest) variations in composition between thinner and thicker films. For the purposes of comparison, we compare the total ("start to end") deposition charges and corresponding mass changes, expressed as $\Delta \mathrm{m} . \mathrm{nF} / \mathrm{Q}\left(\mathrm{g} \mathrm{mol}^{-1}\right)$, where the value of $\mathrm{n}=2$ (and thus the resultant normalised mass) relates to a single aniline unit. For PANI deposition we find $\Delta \mathrm{m} \cdot \mathrm{nF} / \mathrm{Q}=290 \mathrm{~g} \mathrm{~mol}^{-1}$ and for PANI/MWCNT we find $\Delta \mathrm{m} . \mathrm{nF} / \mathrm{Q}=$ $30 \mathrm{~g} \mathrm{~mol}^{-1}$. These should be compared with the value of $91 \mathrm{~g} \mathrm{~mol}^{-1}$ predicted for a compact solvent-free ("dry") slab of PANI (in the undoped state for which the measurement is made).

In the case of pure PANI, the difference must be attributed to solvent incorporation: simple arguments show that this is to the extent of ca. 9 water molecules per aniline unit. Assuming a density of unity, the deposition mass change corresponds to a film thickness of ca. $300 \mathrm{~nm}$, which is below the acoustic decay length ${ }^{110}$, consistent with the gravimetric interpretation of the QCM frequency response. When interpreting the normalised mass change for PANI/MWCNT, there are additional factors to consider: the mass contribution of incorporated MWCNTs, their influence on film solvation and any change in electrodeposition efficiency. If the effect of the nanotubes were total solvent exclusion, but with no drop in polymer deposition efficiency, the normalised mass change would be in excess of $91 \mathrm{~g} \mathrm{~mol}^{-1}$ by an amount representing the carbon nanotube content. The fact that the observed value is different to that for PANI demonstrates nanotube inclusion, and 
the fact that it is below $91 \mathrm{~g} \mathrm{~mol}^{-1}$ indicates both dramatic solvent exclusion (de-wetting) and decreased deposition efficiency.

\section{Electrodeposition of PANI and PANI/MWCNT from Ethaline}

Initial attempts to deposit PANI and composite films from ETH200 solutions of monomer (also containing $1 \mathrm{M} \mathrm{H}_{2} \mathrm{SO}_{4}$ ) were not successful, in the sense that the voltammetric responses were not typical of PANI films. Varying the component concentrations, we arrived at an optimum composition of $1 \mathrm{M}$ aniline / $0.5 \mathrm{M} \mathrm{H}_{2} \mathrm{SO}_{4} / \mathrm{ETH} 400$. The additional Eg in the ETH400 formulation decreases solution viscosity significantly, thus improving solution transport properties. Following the format of Figures 2 and 3, Figures 4 and 5 show representative EQCM data acquired during the potentiodynamic deposition of PANI and PANI/MWCNT films, respectively, from this DES formulation.

The first, qualitative, observation based on the i-E and Q-E responses is that PANI and, more importantly, PANI/MWCNT film deposition is successful and generates films with good electroactivity. Comparison of the cathodic charge involved in (reversible) reduction of the film and the integrated (irreversible) charge consumed in deposition of the film yields ratios of 0.21 and 0.18 , respectively, for PANI and PANI/MWCNT systems. Quantitative deposition and full reduction across both redox processes is associated with a ratio of 0.5 ; we deduce that there is substantial oligomer loss to solution.

At the end of film deposition, the peak acoustic admittance is decreased by $20-25 \%$ compared to that for the bare electrode in the deposition solutions; the decrease at earlier times during deposition is less. These responses support gravimetric interpretation of the frequency responses, as indicated by the axis labels for the QCM responses of panels $b$ of Figures 4 and 5. These mass change $v s$ potential plots show the progressive accumulation of film on the electrode surface, with the least deposition during the first cycle, consistent with the presence of a nucleation loop in the i-E responses of panels a.

The mass change vs charge plots involve different absolute magnitudes of each quantity for the polymer and composite films but we focus on the relative changes, i.e. slope. Quantitatively, the value of $\Delta \mathrm{m} . \mathrm{nF} / \mathrm{Q}$ is $410 \mathrm{~g} \mathrm{~mol}^{-1}$ for PANI and $255 \mathrm{~g} \mathrm{~mol}^{-1}$ for PANI/MWCNT. Similar to the case of aqueous deposition, the MWCNTs significantly 
decrease film wettability, although the solvent content is higher for Ethaline than water in pure and composite films; this is advantageous for redox switching.

Having arrived at a protocol for composite film deposition from the DES, we now consider film redox state changes in background electrolyte; representative data for the PANI and PANI/MWCNT films exposed to $1 \mathrm{M} \mathrm{H}_{2} \mathrm{SO}_{4} /$ ETH200 are shown in Figure 6. We note that, in the absence of acid, the voltammograms (not shown) indicate low film electroactivity and an ohmic-type character during the reduction half cycle; it is clear that protons are required (see below). For both the polymer and composite films, there is a significant "first cycle" effect (compare the black trace with subsequent traces) but, while this evolution of film properties continues for some time for PANI, it is essentially complete in one cycle for the composite. This type of effect is generally attributed to equilibration of the film with its environment; the composite film has the better performance. Further, the PANI response shows progressive separation of the anodic and cathodic peaks, indicative of decreasing charge transport capability.

Gravimetric data provide an explanation for these observations. During the course of the PANI film experiment of Figure 6a, the film mass (measured for the reduced film) decreased by $1.73 \mu \mathrm{g}$. From the mass change $v s$ charge data for deposition and the coulometric assay, we deduce that the electrolyte content of the reduced film, as deposited, was $3.04 \mu \mathrm{g}$. Under the non-equilibrium conditions of continuous cycling, the film has thus been depleted of ca. $57 \%$ of its electrolyte; this will undoubtedly inhibit charge transport. In contrast, for the PANI/MWCNT experiment of Figure 6b, the film mass (again measured for the reduced film) increased by $4.6 \mu \mathrm{g}$, compared to the initial electrolyte content of $2.75 \mu \mathrm{g}$. Under the non-equilibrium conditions of continuous cycling, the composite film has more than doubled its internal electrolyte content. This type of electrolyte "pumping" under non-equilibrium conditions has been observed for polypyrrole films immersed in electrolytes with disparate ion sizes ${ }^{35,36}$.

\section{Electrodeposition of PANI from Oxaline}

Following on from the previous section, we have sought to grow the PANI films in DES media so as to either incorporate some of the charge carriers in the DES or form a polymer morphology that facilitates their transfer from solution to polymer phase. The DES 
Oxaline, with the formulation $\mathrm{Ox}: \mathrm{ChCl}=1: 1$, was chosen for this purpose for two reasons. First, it has labile protons that facilitate polymer formation (see Figures 4 and 5 , above). Second the oxalic acid group is a sufficiently strong acid to sustain polymer growth without the need for addition of extrinsic acid solution (commonly $\mathrm{H}_{2} \mathrm{SO}_{4}$, as above); this has the desirable effect of simplifying the number of components in the electrolyte system.

Figure 7a shows representative data for potentiodynamic deposition of a PANI film from $0.8 \mathrm{M}$ aniline / Oxaline. These data show a well-defined set of quasi-reversible redox curves corresponding to the characteristic features of PANI. These are noticeably more well-defined than in the case where PANI is formed in $2 \mathrm{Eg}: \mathrm{ChCl}$ (see above). The evolution of the redox polymer is even and consistent in each of the 20 cycles.

\section{Cycling of Oxaline-deposited PANI in DES and aqueous media}

Figure $7 \mathrm{~b}$ shows the i-E responses to a series of medium transfer experiments for the Oxaline-deposited PANI film of Figure 7a. From the outset, the PANI film shows well defined voltammetric features in neat (monomer-free) $\mathrm{Ox}: \mathrm{ChCl}$; there is some change in wave shape with redox cycling but essentially no loss of charge storage capacity. The same film was then rinsed in deionised water and cycled in aqueous sulphuric acid. Finally, the film was rinsed again, returned to $\mathrm{Ox}: \mathrm{ChCl}$ and cycled again. Over the period of 20 cycles the shape and definition of the two electron transfer processes changes somewhat; we speculate this is due to pore-blocking in the polymer structure that restricts the flow of charge carriers and, in this case, oxalic acid. When the film is transferred to aqueous electrolyte the two electron transfer processes are again clearly visible. (There is a potential shift, but this is mainly a manifestation of the different reference electrodes necessarily used in the two media.) This response was seen to be stable over the period of the 20 repetitive scans. Since both oxalic acid and $\mathrm{ChCl}$ are soluble in water it is likely that the polymer may be swelled in the presence of water and that this would facilitate the leaching of the DES components, allowing for more rapid charge-carrier and solvent movement in the aqueous sulphuric acid. However, another explanation might be that the polymer is changed in some chemical or physical process by the transition from DES to aqueous medium. To exclude this possibility, the PANI film was rinsed, returned to and again cycled in the $\mathrm{Ox}: \mathrm{ChCl}$. Here an i-E response emerges that is very similar to the original i-E response. Thus, we conclude that there has been no chemical change in the 
PANI film that accounts for the different responses in the two media. Rather, the different voltammetric responses over the same time scales are a reflection of the wettability of the polymer film and the distinctive ion and solvent exchange processes in the DES and aqueous electrolytes.

Whilst $\mathrm{Ox}: \mathrm{ChCl}$ is seen to be a good DES medium from which to prepare the PANI film, it does not necessarily represent an ideal choice for a long-term electrolyte to sustain repetitive cycling of the polymer between charge states. This is because of degradation caused by the acidic groups of the DES to either the PANI film or to the supporting structures, membranes or fabric of a practical device such as a battery cell or capacitor. In this case we have chosen to study the cycling characteristics of these PANI films in the less chemically aggressive environment provided by the DES 2Eg: $\mathrm{ChCl}$ (Ethaline) in comparison with the same film in aqueous sulphuric acid.

The data presented in Figure 8 show the growth and cycling of two PANI films. One of these was grown in Ox:ChCl DES, Figure 8a, and the other was grown in aqueous $\mathrm{H}_{2} \mathrm{SO}_{4}$, Figure $8 \mathrm{~d}$. After growth, the films were each cycled in their native, monomer-free growth electrolyte then successively in the alternative medium and then returned to the original electrolyte. In Figure $8 \mathrm{~b}$ we see the voltammetric responses for the film grown in $\mathrm{Ox}: \mathrm{ChCl}$, then cycled successively in $2 \mathrm{Eg}: \mathrm{ChCl}, \mathrm{H}_{2} \mathrm{SO}_{4}$ and finally $2 \mathrm{Eg}: \mathrm{ChCl}$. In contrast for Figure 8e we see the voltammetric response for a film grown in aqueous $\mathrm{H}_{2} \mathrm{SO}_{4}$ and then cycled successively in aqueous $\mathrm{H}_{2} \mathrm{SO}_{4}, 2 \mathrm{Eg}$ : $\mathrm{ChCl}$ and finally aqueous $\mathrm{H}_{2} \mathrm{SO}_{4}$. For each set of i-E curves, the corresponding specific capacitance data were calculated from the integrated response and are presented in Figure 8c and Figure 8f.

The film grown in $\mathrm{Ox}: \mathrm{ChCl}$, Figure $8 \mathrm{a}, 8 \mathrm{~b}$ and $8 \mathrm{c}$, shows well defined, even and consistent growth similar to that shown in Figure 7a. When this film is transferred to 2Eg: $\mathrm{ChCl}$, Figure $8 \mathrm{~b}$, the response remains similar although the peak currents are somewhat lower in $2 \mathrm{Eg}: \mathrm{ChCl}$. This is, in part, due to an increase in solution viscosity but also is a consequence of low proton activity in $2 \mathrm{Eg}: \mathrm{ChCl}$ compared to $\mathrm{Ox}: \mathrm{ChCl}$. The initial specific capacitance measured in this film is $540 \mathrm{~F} \mathrm{~g}^{-1}$ (where polymer mass is determined based on a coulometric assay of the amount initially deposited) and, over the course of 100 cycles, this drops to ca. $500 \mathrm{~F} \mathrm{~g}^{-1}$. When this film is transferred to aqueous $\mathrm{H}_{2} \mathrm{SO}_{4}$, an increase in electroactivity is observed, as reflected in the magnitude of the peak 
currents and the specific capacitance. Additionally, a potential shift is observed as consequence of the shift in reference potential. The specific capacitance is initially measured at $580 \mathrm{~F} \mathrm{~g} \mathrm{~g}^{-1}$ but this drops sharply to $350 \mathrm{~F} \mathrm{~g}^{-1}$ after 100 cycles. This type of activity loss is typical of PANI films where electrolyte components become trapped when the free-volume of the film is reduced by expulsion of electrolyte/solvent. Electroactivity of the film is not recovered during subsequent cycling of the film in $2 \mathrm{Eg}$ : $\mathrm{ChCl}$ : the specific capacitance is less than $100 \mathrm{~F} \mathrm{~g}^{-1}$ after 100 cycles.

For this case, we have observed that the film capacitance and cycling characteristics do not change substantially upon transfer from DES to water but that subsequent cycling in aqueous electrolyte does result in capacity loss that cannot be recovered in DES. In contrast, the film grown in aqueous $\mathrm{H}_{2} \mathrm{SO}_{4}$, shows a slightly more-well defined i-E response with a concomitant increase in specific capacitance, to $600 \mathrm{~F} \mathrm{~g}^{-1}$. Again, significant fading occurs, after 100 cycles the specific capacitance is decreased to $570 \mathrm{~F}$ $\mathrm{g}^{-1}$. When this is transferred to $2 \mathrm{Eg}$ : $\mathrm{ChCl}$ electrolyte significant activity loss is observed. Some of this can be accounted for by the increase in solution viscosity although it is also likely that the mobility of the charge carriers in the DES, $\mathrm{Ch}^{+}$and the complex anion $\mathrm{Eg}_{2}: \mathrm{Cl}^{-}$, are lower than those in aqueous solution. No clear voltammetric features are seen and the specific capacitance drops to $450 \mathrm{~F} \mathrm{~g}^{-1}$, fading rapidly to $150 \mathrm{~F} \mathrm{~g}^{-1}$ after 100 cycles. The electroactivity is substantially recovered on subsequent transfer back to in aqueous $\mathrm{H}_{2} \mathrm{SO}_{4}$, but again this fades rapidly during cycling.

In summary, here electroactivity of the film is diminished by transfer from aqueous $\mathrm{H}_{2} \mathrm{SO}_{4}$ to $2 \mathrm{Eg}: \mathrm{Cl}$ and, although substantially recovered on return to aqueous $\mathrm{H}_{2} \mathrm{SO}_{4}$, the electroactivity fades rapidly with cycling in the aqueous medium. From these data it is clear that the neat PANI film does not function particularly well as a charge storage membrane in either scenario.

The underlying mechanisms for these switching processes are distinct. For a PANI film (coverage, $\Gamma=231 \mathrm{nmol} \mathrm{cm}{ }^{-2}$ ) deposited from aqueous $1 \mathrm{M} \mathrm{H}_{2} \mathrm{SO}_{4}$, then exposed to the sequence of monomer-free electrolytes $0.5 \mathrm{M} \mathrm{H}_{2} \mathrm{SO}_{4}$, then Ethaline, then $0.5 \mathrm{M} \mathrm{H}_{2} \mathrm{SO}_{4}$, the apparent molar mass changes associated with film oxidation were, respectively, +24 , -23 and $+24 \mathrm{~g} \mathrm{~mol}^{-1}$ (see Figure 9a). These values should be compared with $+97 \mathrm{~g} \mathrm{~mol}^{-1}$ for $\mathrm{HSO}_{4}^{-}$entry $-104 \mathrm{~g} \mathrm{~mol}^{-1}$ for choline $\left(\mathrm{as}^{+} \mathrm{Ch}^{+}\right.$exit. In the aqueous electrolyte, it is 
widely recognized that solvent transfer occurs; this is most likely the origin of the less than anticipated (based solely on Faraday's law) mass change. In the DES, choline cation exit is the dominant (ca. 70\%) process. For a PANI film with coverage also in the subacoustic decay length regime $\left(\Gamma=120 \mathrm{nmol} \mathrm{cm}{ }^{-2}\right)$ but deposited from Oxaline, then exposed to the sequence of monomer-free electrolytes Ethaline, then $0.5 \mathrm{M} \mathrm{H}_{2} \mathrm{SO}_{4}$, then Ethaline, the apparent molar mass changes associated with film oxidation were, respectively, $-251,+96$ and $-179 \mathrm{~g} \mathrm{~mol}^{-1}$ (see Figure 9b). Comparing these values with the molar masses of $\mathrm{Ch}^{+}$and $\mathrm{HSO}_{4}{ }^{-}$, these are the dominant mobile species in Ethaline and aqueous $\mathrm{H}_{2} \mathrm{SO}_{4}$ media respectively.

The common pattern is that maintenance of electroneutrality is anion dominated in aqueous medium and cation dominated in the DES. However, the degree of dominance is more pronounced for the film deposited from Oxaline. This prompts a qualitative revisitation of the PANI deposition data in Figures 2 and 4 (panels d). In the aqueous media (Figure 2), we see that the short sections of the mass change $v s$ charge curves during film reduction show mass decreases, consistent with anion ejection. Contrastingly, in the DES medium (Figure 4), the corresponding sections of the curve are essentially flat; the comparison is not perfect, since it was necessary to use Ethaline 400 for film deposition. A similar pattern is seen when comparing the PANI/MWCNT composite deposition in aqueous (Figure 3) and DES (Figure 5) media; the latter is particularly striking.

\section{Cycling of Oxaline-deposited PANI composites in DES and aqueous media}

Further experiments were carried out where the PANI films were prepared with incorporated particles of either graphite flakes $(2-12 \mu \mathrm{m}), \mathrm{MoO}_{2}$ particles $(1-20 \mu \mathrm{m})$, or a combination of both. Here the intent was that the incorporation of the particles in the polymer film would both contribute to bulk conductivity, therefore allowing access to all internal and external regions of the film, and also support the polymer architecture and facilitate movement of charged species (as well as solvent) in and out of the membrane.

The data presented in Figure 10 are structured in a similar way to those in Figure 8 resulting from the same experimental methodology. The data are shown for a PANI film grown with incorporated graphite $(75 \%)$ and $\mathrm{MoO}_{2}(25 \%)$ exposed to either $\mathrm{Ox}: \mathrm{ChCl}$ (Figure 10a, b and c) or aqueous $\mathrm{H}_{2} \mathrm{SO}_{4}$ (Figure 10d, e and f). Here a contrasting picture 
emerges. First, for the film grown in $\mathrm{Ox}: \mathrm{ChCl}$ the electroactivity, whether expressed in terms of voltammetric response or specific capacitance, is much more stable than that observed for the neat PANI film. Second, although an increase in specific capacitance is observed in transferring from DES to water (Figure $10 \mathrm{~b}$ and $\mathrm{c}$ ), this reverts to approximately the original value when transferred back into DES. This indicates that the presence of the $\mathrm{Gr}$ and $\mathrm{MoO}_{2}$ particles acts to mitigate the effects of fading in the neat PANI film. A similar pattern is observed for the composite film grown in aqueous $\mathrm{H}_{2} \mathrm{SO}_{4}$.

The data from these two experiments (shown in Figure 8 and Figure 10) are summarised together with data for other composite films containing only $\mathrm{Gr}$ or $\mathrm{MoO}_{2}$, in Figure 11. From the data presented we can conclude that the PANI/Gr/ $\mathrm{MoO}_{2}$ composite film functions more effectively and with better long-term stability in both aqueous and DES electrolytes than do the neat PANI film or either of the other composite materials.

\section{Morphological and compositional data for PANI composites}

Interpretation of the electrochemical behaviour indicated would naturally be supported by compositional data that shows the presence of the particulates and morphological data that show the influence of their presence. The obvious approach is to use SEM imaging (see Figure 12), accompanied by EDX elemental analysis. Horizontal comparisons of the images in Figure 12 show that the deposition medium undoubtedly influences the film morphology. This is correlated with the differing solvent contents of the films, as evidenced by the slopes of the EQCM mass change $v s$ charge plots. However, particularly in the case of the composites, it is not necessarily clear whether film wettability (as influenced by the presence/absence of particulates) dictates polymer structure or steric factors (dictated by particulates) dictate polymer structure and thence wettability. The MWCNTs are too small to see at the magnification used here, and in any case are likely to be wrapped in polymer, but the $\mathrm{MoO}_{2}$ particles and graphite flakes are clearly visible.

In the case of the MWCNTs and graphite, elemental analysis cannot provide unambiguous evidence for their presence, since one is seeking carbon in a largely carbon matrix. However, there is unambiguous evidence of the presence of $\mathrm{MoO}_{2}$, as shown by the EDX data of Figure 13. 


\section{CONCLUSIONS}

The overall aim of the present study is an understanding of how changing electroactive film composition and electrolyte type influenced (polyaniline) film wettability by the bathing electrolyte. The initial accomplishments here relate to aspects of polyaniline film fabrication, as one diverges from the widely studied deposition of polyaniline from monomer solution in aqueous acid media. Focusing on the electrolyte, we have identified conditions for deposition from DES media (Ethaline and Oxaline). In the case of Ethaline (an aprotic medium) it was necessary to add sulfuric acid and additional ethylene glycol (use of ETH400, rather than the standard ETH200, formulation). However, in the case of Oxaline, the protic nature of the medium (via oxalic acid) meant that it was not necessary to add additional strong acid; this has the advantage of avoiding strong aqueous inorganic acids that may degrade the film in long-term use.

Turning to the film, we have identified conditions under which polyaniline-based composites containing MWCNTs, graphite flakes, molybdenum dioxide particles and mixtures of graphite and molybdenum dioxide can be deposited. For the larger graphite and molybdenum (cf. MWCNT) particulates, it was necessary to pre-coat the electrode with a thin film of polymer, then add the particulates and a second layer of polymer; this was achieved for aqueous and DES media. SEM imaging reveals morphologies that vary significantly with both deposition medium (aqueous vs. DES) and with the inclusion of particulates. Based on size, the graphite flakes can be observed directly, but the MWCNTs cannot. The unique element (Mo) in PANI/MoO2 permits identification of molybdenum dioxide directly by EDX.

For all the combinations (of electrolyte and film) studied, evaluation of coulometric (and for PANI/MWCNT films gravimetric) assays showed that the films are deposited less than quantitatively, but with acceptable yield, based on monomer consumption. PANI/MWCNT films in aqueous medium are much less solvated than PANI films. In potentiodynamic deposition of PANI and PANI/MWCNT films from Ethaline, the gravimetric response during the cathodic half cycle reveals cation (choline) involvement in the maintenance of electroneutrality; this contrasts with the common case of anion transfer upon oxidation of conducting polymers. 
Redox cycling of Ethaline-deposited PANI and PANI/MWNCT films in monomer-free Ethaline shows evolution of current-voltage characteristics, but somewhat differently. The polymer films evolve over many cycles in a direction of decreasing reversibility, while the composite films evolve more rapidly with little change in reversibility. Gravimetric (QCM) data show that film electrolyte content (and thus wettability) change significantly, but in opposite directions: cycling the pure polymer results in progressive electrolyte loss, while cycling the polymer composite results in progressive electrolyte accumulation.

Medium transfer experiments, in which PANI and PANI composite films were transferred between aqueous and DES media, and redox cycled in each, were used to explore film longevity and stability of charge storage response. "Bracketed" experiments, in which the final phase involves return to the initial electrolyte of exposure, are particularly useful in evaluating longevity. Fading of electroactivity is most obvious when the films are cycled in aqueous acid and this is not always recovered by return to DES. Viewed across a wide range of parameters and circumstances, the summary is that deposition from Oxaline is optimal, and that inclusion of graphite of molybdenum dioxide enhances durability of charge storage/recovery; inclusion of both graphite and molybdenum dioxide is optimal.

\section{ACKNOWLEDGEMENTS}

We thank the Republic of Turkey Ministry of National Education and the Ministry of Higher Education and Scientific Research in Kurdistan (HCDP Program), respectively, for studentships for AU and HKI. The authors acknowledge the support received from the Energy Research Accelerator (ERA), funded jointly by Innovate UK and industrial partners to foster collaboration between academia and business. 


\section{REFERENCES}

1 T. A. Skotheim and R. J. Reynolds, Handbook of Conjugated Polymers, CRC Press, Boca Raton, FL, 2007.

2 R. A. Bull, F. R. Fan and A. J. Bard, J. Electrochem. Soc., 1983, 130, 1636-1638 (DOI:10.1149/1.2120053).

3 A. F. Diaz and J. A. Logan, J Electroanal Chem, 1980, 111, 111-114 (DOI: 10.1016/S0022-0728(80)80081-7).

4 G. Tourillon and F. Garnier, J. Electrochem. Soc., 1983, 130, 2042-2044 (DOI:10.1149/1.2119517).

5 K. Kaneto, K. Yoshino and Y. Inuishi, Solid State Commun., 1983, 46, 389-391 (DOI:10.1016/0038-1098(83)90454-4).

6 R. J. Waltman, J. Bargon and A. F. Diaz, J. Phys. Chem., 1983, 87, 1459-1463 (DOI:10.1021/j100231a035).

7 A. R. Hillman, K. S. Ryder, V. C. Ferreira, C. J. Zaleski and E. Vieil, Electrochim. Acta, 2013, 110, 418-427 (DOI:10.1016/j.electacta.2013.07.120).

8 G. Schiavon, G. Zotti and G. Bontempelli, J Electroanal Chem, 1985, 186, 191-199 (DOI:10.1016/0368-1874(85)85765-8).

9 H. A. A. ElRahman and J. W. Schultze, J Electroanal Chem, 1996, 416, 67-74 (DOI:10.1016/S0022-0728(96)04718-3).

10 Y. Z. Su, Y. P. Niu, Y. Z. Xiao, M. Xiao, Z. X. Liang and K. C. Gong, Journal of Polymer Science Part A-Polymer Chemistry, 2004, 42, 2329-2339

(DOI:10.1002/pola.20072).

11 T. K. Das and S. Prusty, Polym. -Plast. Technol.Eng., 2012, 51, 1487-1500 (DOI:10.1080/03602559.2012.710697).

12 U. Lange, N. V. Roznyatouskaya and V. M. Mirsky, Anal. Chim. Acta, 2008, 614, 126 (DOI:10.1016/j.aca.2008.02.068).

13 X. Li, Y. Wang, X. Yang, J. Chen, H. Fu and T. Cheng, Trac-Trends in Analytical Chemistry, 2012, 39, 163-179 (DOI:10.1016/j.trac.2012.06.003).

14 U. Lange, N. V. Roznyatouskaya and V. M. Mirsky, Anal. Chim. Acta, 2008, 614, 126 (DOI:10.1016/j.aca.2008.02.068).

15 J. L. Camalet, J. C. Lacroix, S. Aeiyach, K. ChaneChing and P. C. Lacaze, J Electroanal Chem, 1996, 416, 179-182 (DOI:10.1016/S0022-0728(96)01012-1).

16 D. E. Tallman, G. Spinks, A. Dominis and G. G. Wallace, Journal of Solid State Electrochemistry, 2002, 6, 73-84 (DOI:10.1007/s100080100212). 
17 V. Brusic, M. Angelopoulos and T. Graham, J. Electrochem. Soc., 1997, 144, 436442 (DOI:10.1149/1.1837428).

18 D. Sazou and C. Georgolios, J Electroanal Chem, 1997, 429, 81-93

(DOI:10.1016/S0022-0728(96)05019-X).

19 R. Racicot, R. Brown and S. C. Yang, Synth. Met., 1997, 85, 1263-1264

(DOI:10.1016/S0379-6779(97)80232-9).

20 K. Gurunathan, A. V. Murugan, R. Marimuthu, U. P. Mulik and D. P. Amalnerkar, Mater. Chem. Phys., 1999, 61, 173-191 (DOI:10.1016/S0254-0584(99)00081-4).

21 A. A. Syed and M. K. Dinesan, Talanta, 1991, 38, 815-837 (DOI:10.1016/00399140(91)80261-W).

22 G. Inzelt, M. Pineri, J. W. Schultze and M. A. Vorotyntsev, Electrochim. Acta, 2000, 45, 2403-2421 (DOI:10.1016/S0013-4686(00)00329-7).

23 G. Spinks, V. Mottaghitalab, M. Bahrami-Saniani, P. Whitten and G. Wallace, Adv Mater, 2006, 18, 637-640 (DOI:10.1002/adma.200502366).

24 J. Heinze, B. A. Frontana-Uribe and S. Ludwigs, Chem. Rev., 2010, 110, 4724-4771 (DOI:10.1021/cr900226k).

25 M. A. Vorotyntsev, E. Vieil and J. Heinze, J Electroanal Chem, 1998, 450, 121-141 (DOI:10.1016/S0022-0728(97)00623-2).

26 Y. H. Lin, X. L. Cui and J. Bontha, Environ. Sci. Technol., 2006, 40, 4004-4009 (DOI:10.1021/es052148u).

27 P. Burgmayer and R. W. Murray, J. Phys. Chem., 1984, 88, 2515-2521 (DOI:10.1021/j150656a017).

28 V. M. Schmidt and J. Heitbaum, Electrochim. Acta, 1993, 38, 349-356 (DOI:10.1016/0013-4686(93)85150-W).

29 Q. J. Xie, S. Kuwabata and H. Yoneyama, J Electroanal Chem, 1997, 420, 219-225 (DOI:10.1016/S0022-0728(96)04777-8).

30 C. Lopez, M. F. M. Viegas, G. Bidan and E. Vieil, Synth. Met., 1994, 63, 73-78 (DOI:10.1016/0379-6779(94)90252-6).

31 Q. X. Zhou, C. J. Kolaskie and L. L. Miller, J Electroanal Chem, 1987, 223, 283-286 (DOI:10.1016/0022-0728(87)85267-1).

32 H. Lee, H. Yang and J. Kwak, J Electroanal Chem, 1999, 468, 104-109 (DOI:10.1016/S0022-0728(99)00037-6).

33 M. D. Levi, C. Lopez, E. Vieil and M. A. Vorotyntsev, Electrochim. Acta, 1997, 42, 757-769 (DOI:10.1016/S0013-4686(96)00340-4). 
34 M. A. Vorotyntsev, E. Vieil and J. Heinze, J Electroanal Chem, 1998, 450, 121-141 (DOI:10.1016/S0022-0728(97)00623-2).

35 S. Bruckenstein, K. Brzezinska and A. R. Hillman, Electrochim. Acta, 2000, 45, 3801-3811 (DOI:10.1016/S0013-4686(00)00467-9).

36 S. Bruckenstein, K. Brzezinska and A. R. Hillman, Physical Chemistry Chemical Physics, 2000, 2, 1221-1229 (DOI:10.1039/a908719b).

37 F. B. Diniz, K. C. S. deFreitas and W. M. deAzevedo, Electrochim. Acta, 1997, 42, 1789-1793 (DOI:10.1016/S0013-4686(96)00378-7).

38 M. A. Lilga, R. J. Orth, J. P. H. Sukamto, S. D. Rassat, J. D. Genders and R. Gopal, Separation and Purification Technology, 2001, 24, 451-466 (DOI:10.1016/S13835866(01)00145-9).

39 S. D. Rassat, J. H. Sukamto, R. J. Orth, M. A. Lilga and R. T. Hallen, Separation and Purification Technology, 1999, 15, 207-222 (DOI:10.1016/S1383-5866(98)00102$6)$.

40 Y. H. Lin and X. L. Cui, Chemical Communications, 2005, , 2226-2228 (DOI:10.1039/b500417a).

41 S. Bruckenstein and A. R. Hillman, J. Phys. Chem., 1988, 92, 4837-4839 (DOI:10.1021/j100328a008).

42 E. Pater, S. Bruckenstein and A. Hillman, Journal of the Chemical Society-Faraday Transactions, 1996, 92, 4087-4092 (DOI:10.1039/ft9969204087).

43 A. R. Hillman, J Solid State Electrochem, 2011, 15, 1647-1660.

44 A. R. Hillman, in Encyclopaedia of Eletrochemistry, ed. A. J. Bard and M. Stratmann, Wiley, New York, 2003, pp.230-289.

45 A. Bund and S. Neudeck, J Phys Chem B, 2004, 108, 17845-17850 (DOI:10.1021/jp0469721).

46 H. N. Dinh and V. I. Birss, J Electroanal Chem, 1998, 443, 63-71 (DOI:10.1016/S0022-0728(97)00470-1).

47 M. Gvozdenovic, B. Jugovic, J. Stevanovic, T. Trisovic and B. Grgur, in Electropolymerization, ed. E. Schab-Balcerzak, Rijeka, InTech, 2011, pp.77-96.

48 M. Matsushita, H. Kuramitz and S. Tanaka, Environ. Sci. Technol., 2005, 39, 38053810 (DOI:10.1021/es040379f).

49 Ren Dandan, J. Xu, Xi Lingling and Z. Yan, J. Chromatogr. Sci., 2011, 49, 612-616.

50 A. M. P. Hussain and A. Kumar, Bull. Mater. Sci., 2003, 26, 329-334

(DOI:10.1007/BF02707455). 
51 Y. Wang, J. Zhang, D. Sheng and C. Sun, Journal of Chromatography a, 2010, 1217, 4523-4528 (DOI:10.1016/j.chroma.2010.04.075).

52 J. Lippe and R. Holze, J Electroanal Chem, 1992, 339, 411-422 (DOI:10.1016/00220728(92)80465-G).

53 S. K. Mondal, K. Barai and N. Munichandraiah, Electrochim. Acta, 2007, 52, 32583264 (DOI:10.1016/j.electacta.2006.09.067).

54 V. V. Abalyaeva and O. N. Efimov, Russian J. Electrochem., 2011, 47, 1307-1316 (DOI:10.1134/S1023193511110036).

55 M. C. Li, C. A. Ma, B. Y. Liu and Z. M. Jin, Electrochemistry Communications, 2005, 7, 209-212 (DOI:10.1016/j.elecom.2004.12.012).

56 G. Zotti, S. Cattarin and N. Comisso, J Electroanal Chem, 1988, 239, 387-396 (DOI:10.1016/0022-0728(88)80293-6).

57 G. Ciric-Marjanovic, Synth. Met., 2013, 177, 1-47

(DOI:10.1016/j.synthmet.2013.06.004).

58 N. Gospodinova and L. Terlemezyan, Progress in Polymer Science, 1998, 23, 1443 1484 (DOI:10.1016/S0079-6700(98)00008-2).

59 S. L. Mu, Synth. Met., 2004, 143, 259-268 (DOI:10.1016/j.synthmet.2003.12.008).

60 D. D. Borole, U. R. Kapadi, P. P. Mahulikar and D. G. Hundiwale, Mater Lett, 2006, 60, 2447-2452 (DOI:10.1016/j.matlet.2006.01.014).

61 S. Yalcinkaya, T. Tueken, B. Yazici and M. Erbil, Progress in Organic Coatings, 2008, 63, 424-433 (DOI:10.1016/j.porgcoat.2008.07.002).

62 G. Inzelt, in Chemical and Electrochemical Synthesis of Conducting Polymers, ed. nonymous 2012, pp.53-60.

63 D. Pathania, G. Sharma, A. Kumar and N. C. Kothiyal, J. Alloys Compounds, 2014, 588, 668-675 (DOI:10.1016/j.jallcom.2013.11.133).

64 M. Bhaumik, A. Maity, V. V. Srinivasu and M. S. Onyango, J. Hazard. Mater., 2011, 190, 381-390 (DOI:10.1016/j.jhazmat.2011.03.062).

65 X. Y. Gong, J. Liu, S. Baskaran, R. D. Voise and J. S. Young, Chemistry of Materials, 2000, 12, 1049-1052 (DOI:10.1021/cm9906396).

66 V. Mottaghitalab, G. M. Spinks and G. G. Wallace, Synth. Met., 2005, 152, 77-80 (DOI:10.1016/j.synthmet.2005.07.154).

67 C. Dhand, S. K. Arya, S. P. Singh, B. P. Singh, M. Datta and B. D. Malhotra, Carbon, 2008, 46, 1727-1735 (DOI:10.1016/j.carbon.2008.07.028). 
68 M. L. Guo, J. H. Chen, J. Li, B. Tao and S. Z. Yao, Anal. Chim. Acta, 2005, 532, 71 77 (DOI:10.1016/j.aca.2004.10.045).

69 X. Luo, A. J. Killard, A. Morrin and M. R. Smyth, Anal. Chim. Acta, 2006, 575, 3944 (DOI:10.1016/j.aca.2006.05.064).

70 W. J. Liou, T. Y. Yang, K. N. Lin, C. H. Yang and H. M. Lin, Semiconductor Materials for Sensing, 2005, 828, 85-95.

71 D. Wei, C. Kvarnstrom, T. Lindfors and A. Ivaska, Electrochemistry Communications, 2007, 9, 206-210 (DOI:10.1016/j.elecom.2006.09.008).

72 H. Zengin, W. S. Zhou, J. Y. Jin, R. Czerw, D. W. Smith, L. Echegoyen, D. L. Carroll, S. H. Foulger and J. Ballato, Adv Mater, 2002, 14, 1480-1483 (DOI:10.1002/1521-4095(20021016)14:203.0.CO;2-O).

73 C. Park, Z. Ounaies, K. A. Watson, R. E. Crooks, J. Smith, S. E. Lowther, J. W. Connell, E. J. Siochi, J. S. Harrison and T. L. S. Clair, Chemical Physics Letters, 2002, 364, 303-308 (DOI:10.1016/S0009-2614(02)01326-X).

74 J. Sandler, M. S. P. Shaffer, T. Prasse, W. Bauhofer, K. Schulte and A. H. Windle, Polymer, 1999, 40, 5967-5971 (DOI:10.1016/S0032-3861(99)00166-4).

75 B. Fragneaud, K. Masenelli-Varlot, A. Gonzalez-Montiel, M. Terrones and J. Y. Cavaille, Chemical Physics Letters, 2006, 419, 567-573

(DOI:10.1016/j.cplett.2005.12.011).

76 S. Banerjee, T. Hemraj-Benny and S. S. Wong, Adv Mater, 2005, 17, 17-29 (DOI:10.1002/adma.200401340).

77 B. Yu, F. Zhou, G. Liu, Y. Liang, W. T. S. Huck and W. Liu, Chemical Communications, 2006, , 2356-2358 (DOI:10.1039/b603878f).

78 M. Baibarac, I. Baltog, C. Godon, S. Lefrant and O. Chauvet, Carbon, 2004, 42, 3143-3152 (DOI:10.1016/j.carbon.2004.07.030).

79 H. Chen, H. Muthuraman, P. Stokes, J. Zou, X. Liu, J. Wang, Q. Huo, S. I. Khondaker and L. Zhai, Nanotechnology, 2007, 18, 415606 (DOI:10.1088/09574484/18/41/415606).

80 T. Welton, Chem. Rev., 1999, 99, 2071-2083 (DOI:10.1021/cr980032t).

81 P. C. Innis, J. Mazurkiewicz, T. Nguyen, G. G. Wallace and D. MacFarlane, Current Applied Physics, 2004, 4, 389-393

(DOI:http://dx.doi.org.ezproxy3.lib.le.ac.uk/10.1016/j.cap.2003.11.056).

82 J. D. Mota-Morales, M. C. Gutierrez, M. Luisa Ferrer, R. Jimenez, P. Santiago, I. C. Sanchez, M. Terrones, F. Del Monte and G. Luna-Barcenas, Journal of Materials Chemistry a, 2013, 1, 3970-3976 (DOI:10.1039/c3ta01020a). 
83 C. Nanjundiah, S. F. McDevitt and V. R. Koch, J. Electrochem. Soc., 1997, 144, 3392-3397 (DOI:10.1149/1.1838024).

84 D. R. Macfarlane, M. Forsyth, P. C. Howlett, J. M. Pringle, J. Sun, G. Annat, W. Neil and E. I. Izgorodina, Acc. Chem. Res., 2007, 40, 1165-1173 (DOI:10.1021/ar7000952).

85 S. Ahmad, M. Deepa and S. Singh, Langmuir, 2007, 23, 11430-11433 (DOI:10.1021/la702442c).

86 K. Sekiguchi, M. Atobe and T. Fuchigami, J Electroanal Chem, 2003, 557, 1-7 (DOI:10.1016/S0022-0728(03)00344-9).

87 S. Mu, J Phys Chem B, 2008, 112, 6344-6349 (DOI:10.1021/jp7117828).

88 P. G. Pickup and R. A. Osteryoung, J. Am. Chem. Soc., 1984, 106, 2294-2299 (DOI:10.1021/ja00320a014).

89 P. G. Pickup and R. A. Osteryoung, J Electroanal Chem, 1985, 195, 271-288 (DOI:10.1016/0022-0728(85)80048-6).

90 T. A. Zawodzinski, L. Janiszewska and R. A. Osteryoung, J Electroanal Chem, 1988, 255, 111-117 (DOI:10.1016/0022-0728(88)80008-1).

91 L. Janiszewska and R. A. Osteryoung, J. Electrochem. Soc., 1987, 134, 2787-2794 (DOI:10.1149/1.2100288).

92 Z. J. Miao, Y. Wang, Z. M. Liu, J. Huang, B. X. Han, Z. Y. Sun and J. M. Du, Journal of Nanoscience and Nanotechnology, 2006, 6, 227-230

(DOI:10.1166/jnn.2006.054).

93 N. Koura, H. Ejiri and K. Takeishi, Denki Kagaku, 1991, 59, 74-75.

94 N. Koura, H. Ejiri and K. Takeishi, J. Electrochem. Soc., 1993, 140, 602-605 (DOI:10.1149/1.2056128).

95 S. Mu, Electrochim. Acta, 2007, 52, 7827-7834

(DOI:10.1016/j.electacta.2007.06.053).

96 D. Wei, C. Kvarnstrom, T. Lindfors and A. Ivaska, Electrochemistry

Communications, 2006, 8, 1563-1566 (DOI:10.1016/j.elecom.2006.07.024).

97 F. F. C. Bazito, L. T. Silveira, R. M. Torresi and S. I. Cordoba de Torresi, Physical Chemistry Chemical Physics, 2008, 10, 1457-1462 (DOI:10.1039/b714458j).

98 M. C. Gutierrez, F. Rubio and F. del Monte, Chemistry of Materials, 2010, 22, 27112719 (DOI:10.1021/cm9023502).

99 H. Maka, T. Spychaj and K. Kowalczyk, J Appl Polym Sci, 2014, 131 (DOI:10.1002/app.40401). 
100 Q. Zhang, K. D. O. Vigier, S. Royer and F. Jerome, Chem. Soc. Rev., 2012, 41, 7108-7146 (DOI:10.1039/c2cs35178a).

101 P. M. V. Fernandes, J. M. Campina, C. M. Pereira and F. Silva, J. Electrochem. Soc., 2012, 159, G97-G105 (DOI:10.1149/2.059209jes).

102 M. A. Skopek, M. A. Mohamoud, K. S. Ryder and A. R. Hillman, Chemical Communications, 2009, , 935-937 (DOI:10.1039/b819084d).

103 K. P. Prathish, R. C. Carvalho and C. M. A. Brett, Electrochemistry

Communications, 2014, 44, 8-11 (DOI:10.1016/j.elecom.2014.03.026).

104 A. R. Hillman and M. A. Mohamoud, Electrochim. Acta, 2006, 51, 6018-6024 (DOI:10.1016/j.electacta.2005.11.054).

105 A. R. Hillman, M. A. Mohamoud and I. Efimov, Anal. Chem., 2011, 83, 5696-5707 (DOI:10.1021/ac200901d).

106 H. Bandey, A. Hillman, M. Brown and S. Martin, Faraday Discuss., 1997, 107, 105-121 (DOI:10.1039/a704278g).

107 A. M. Mohamoud and A. R. Hillman, Electrochim. Acta, 2007, 53, 1206-1216 (DOI:10.1016/j.electacta.2007.01.042).

108 M. A. Atieh, O. Y. Bakather, B. Al-Tawbini, A. A. Bukhari, F. A. Abuilaiwi and M. B. Fettouhi, Bioinorganic Chemistry and Applications, 2010, , 603978 (DOI:10.1155/2010/603978).

109 E. L. Smith, A. P. Abbott and K. S. Ryder, Chem. Rev., 2014, 114, 11060-11082 (DOI:10.1021/cr300162p).

110 M. A. Mohamoud and A. R. Hillman, Journal of Solid State Electrochemistry, 2007, 11, 1043-1050 (DOI:10.1007/s10008-007-0266-8). 


\section{FIGURES}
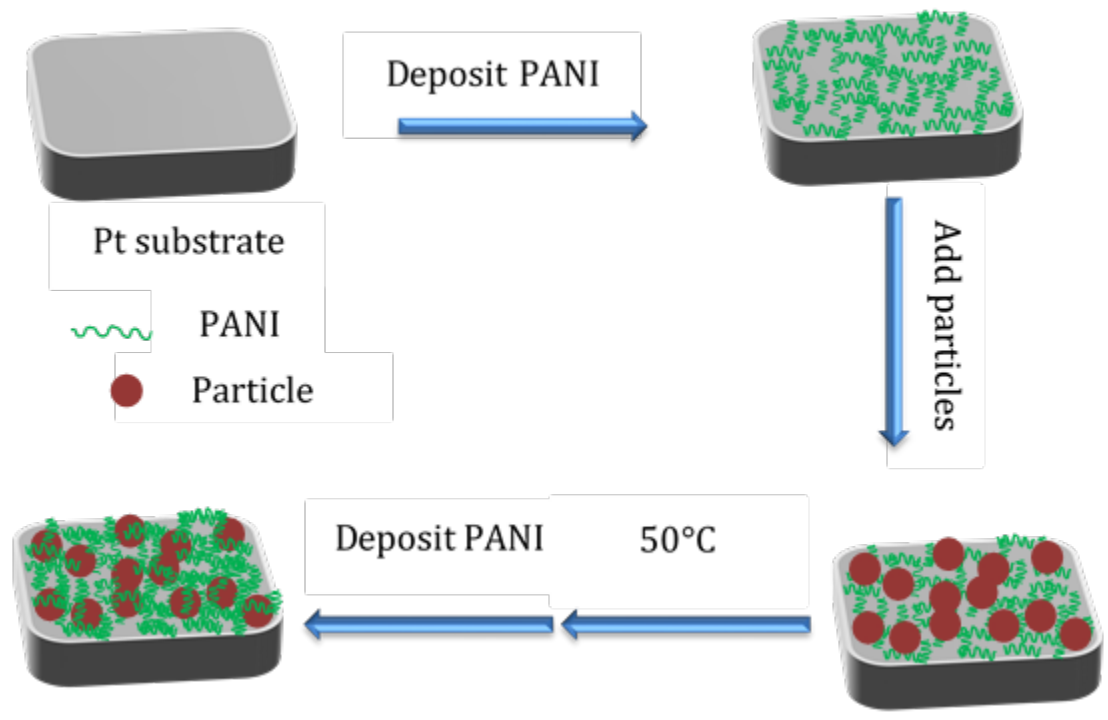

Figure 1: Schematic diagram of the fabrication of $\mathrm{PANI} / \mathrm{MoO}_{2}, \mathrm{PANI} / \mathrm{Gr}$ and $\mathrm{PANI} / \mathrm{Gr} / \mathrm{MoO}_{2}$ composite films. 

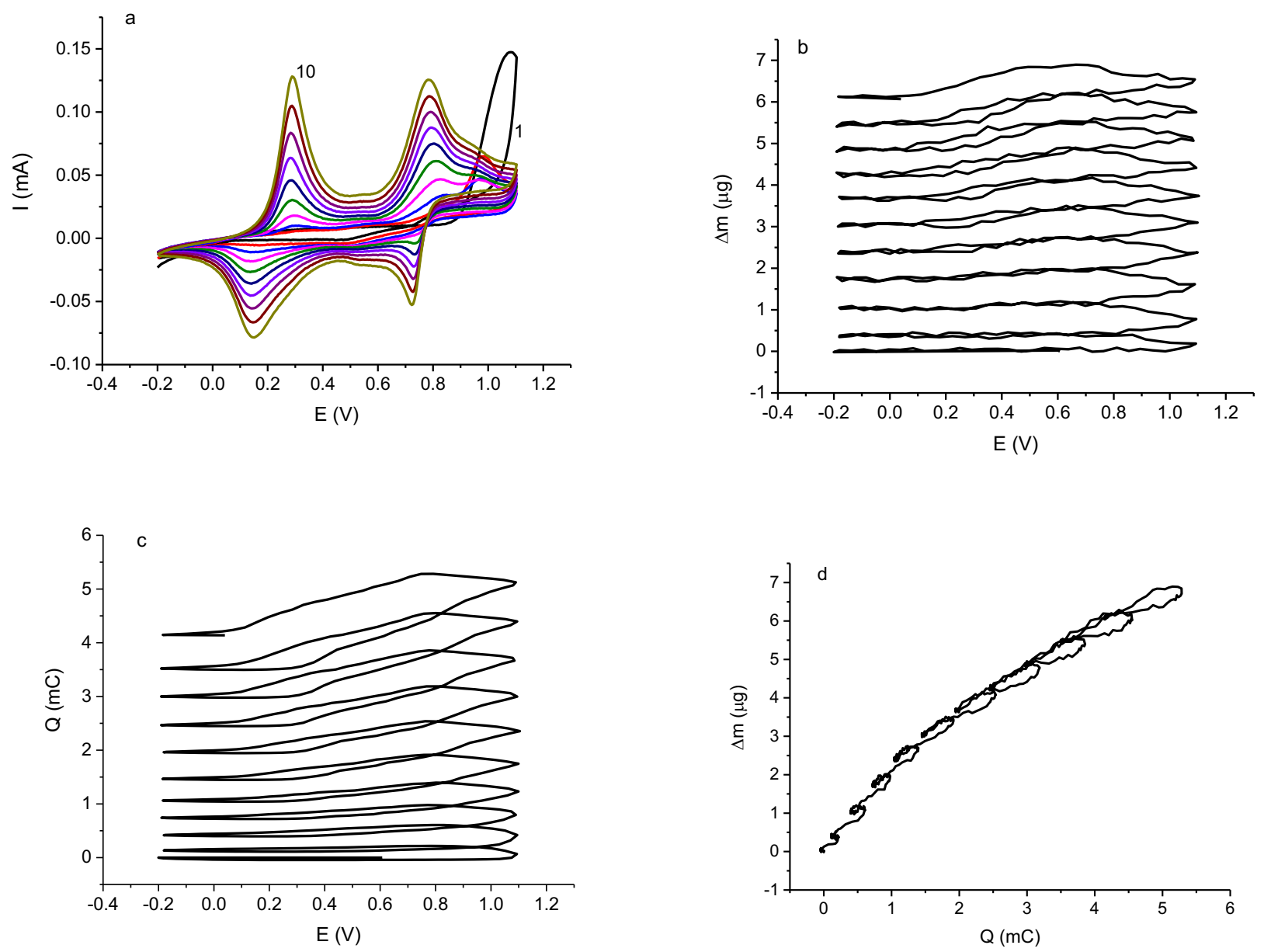

Figure 2: Representative electrochemical responses for potentiodynamic deposition (scan rate, $\mathrm{v}=10 \mathrm{mV} \mathrm{s}^{-1}$ ) of PANI from aqueous $0.1 \mathrm{M}$ aniline / 0.1 $\mathrm{M} \mathrm{H}_{2} \mathrm{SO}_{4}$. (a) i-E; (b) $\Delta \mathrm{m}-\mathrm{E}$; (c ) QE; (d) $\triangle \mathrm{m}-\mathrm{Q}$. Electrode: Au on QCM crystal. 

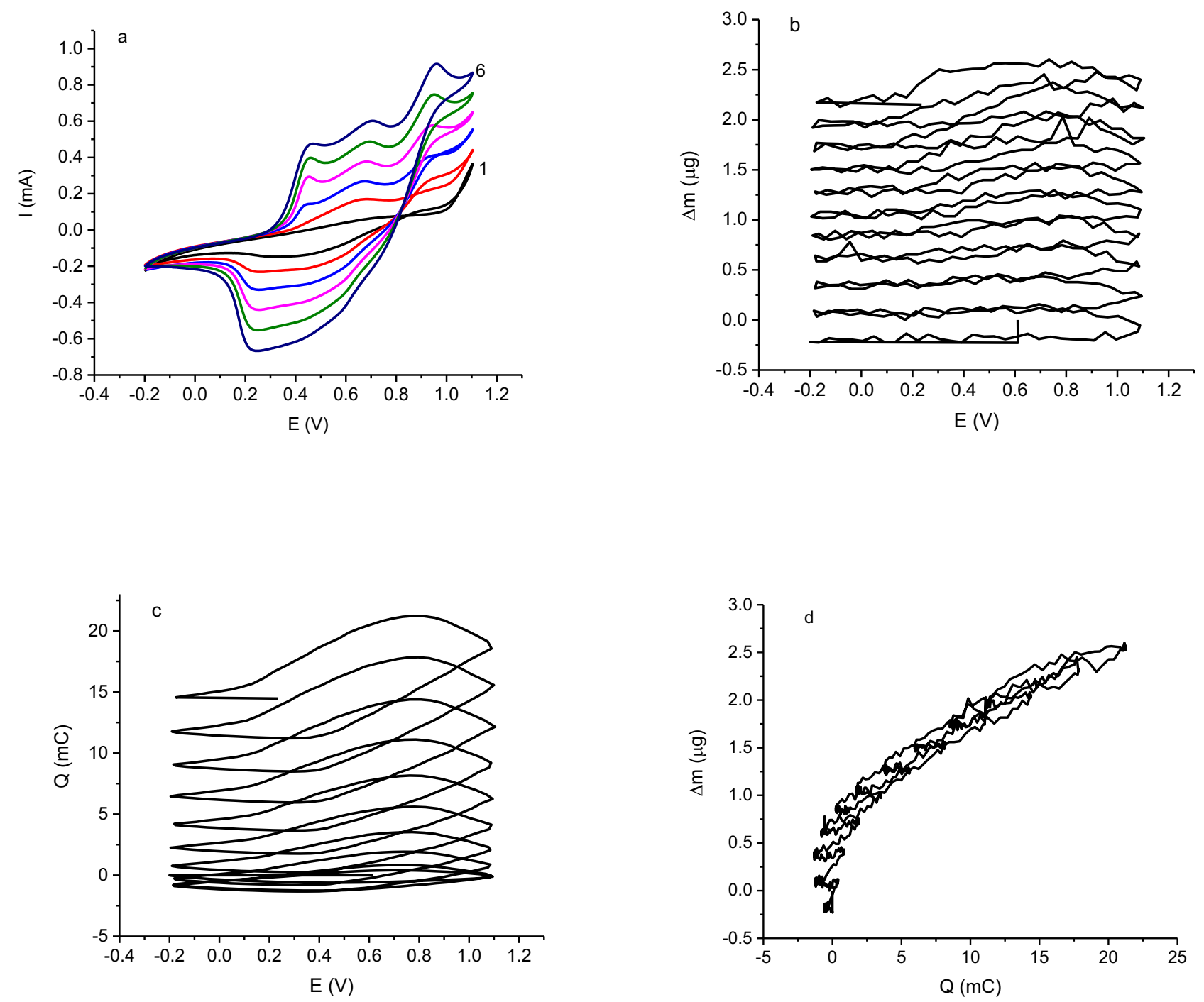

Figure 3: Representative electrochemical responses for potentiodynamic deposition (scan rate, $\mathrm{v}=10 \mathrm{mV} \mathrm{s}^{-1}$ ) of PANI from aqueous $0.1 \mathrm{M}$ aniline / $0.1 \mathrm{M} \mathrm{H}_{2} \mathrm{SO}_{4} / 5 \mathrm{wt} \% \mathrm{MWCNT}$. (a) iE; (b) $\Delta \mathrm{m}-\mathrm{E}$; (c ) Q-E; (d) $\Delta \mathrm{m}-\mathrm{Q}$. Electrode: Au on QCM crystal. 

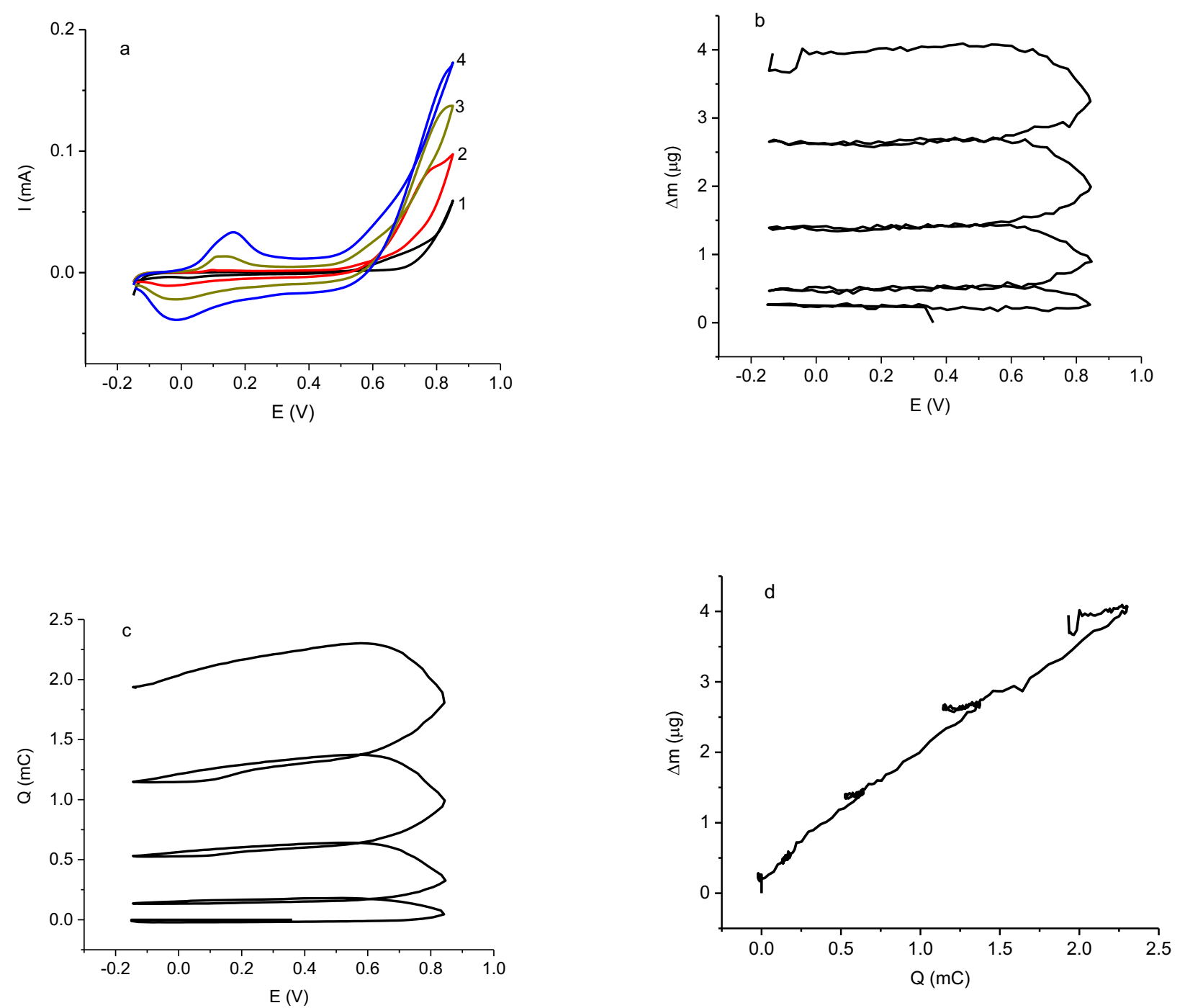

Figure 4: Representative electrochemical responses for potentiodynamic deposition (scan rate, $\mathrm{u}=5 \mathrm{mV} \mathrm{s}^{-1}$ ) of PANI from $1 \mathrm{M}$ aniline / $0.5 \mathrm{M} \mathrm{H}_{2} \mathrm{SO}_{4} / \mathrm{ETH} 400$. (a) i-E; (b) $\Delta \mathrm{m}-\mathrm{E}$; (c ) QE; (d) $\Delta \mathrm{m}-\mathrm{Q}$. Electrode: Pt on QCM crystal. 

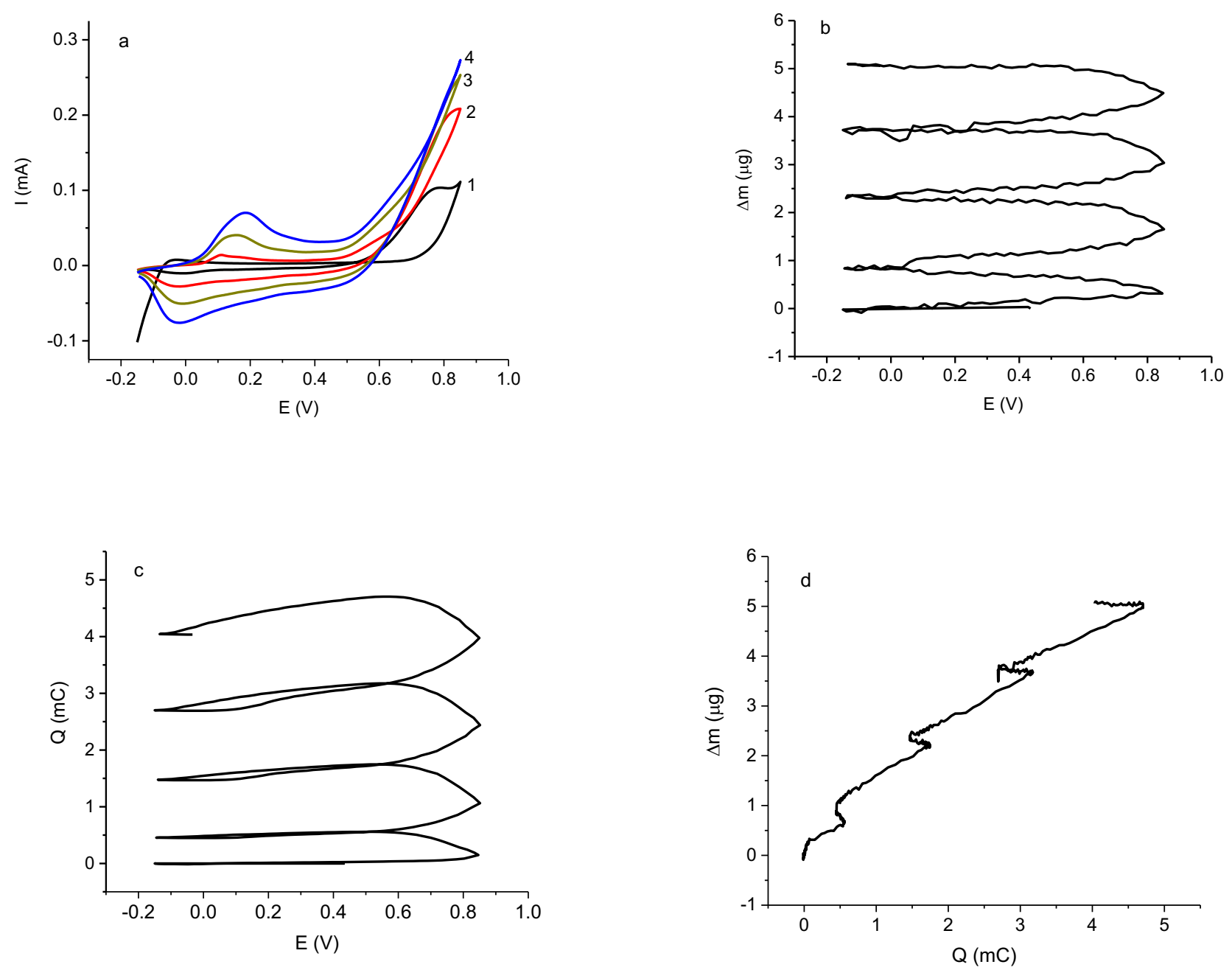

Figure 5: Representative electrochemical responses for potentiodynamic deposition (scan rate, $v=5 \mathrm{mV} \mathrm{s}^{-1}$ ) of PANI from $1 \mathrm{M}$ aniline / $0.5 \mathrm{M} \mathrm{H}_{2} \mathrm{SO}_{4} / \mathrm{ETH} 400 / 1 \mathrm{wt} \%$ MWCNT. (a) i-E; (b) $\Delta \mathrm{m}-\mathrm{E}$; (c ) Q-E; (d) $\Delta \mathrm{m}$-Q. Electrode: Pt on QCM crystal. 

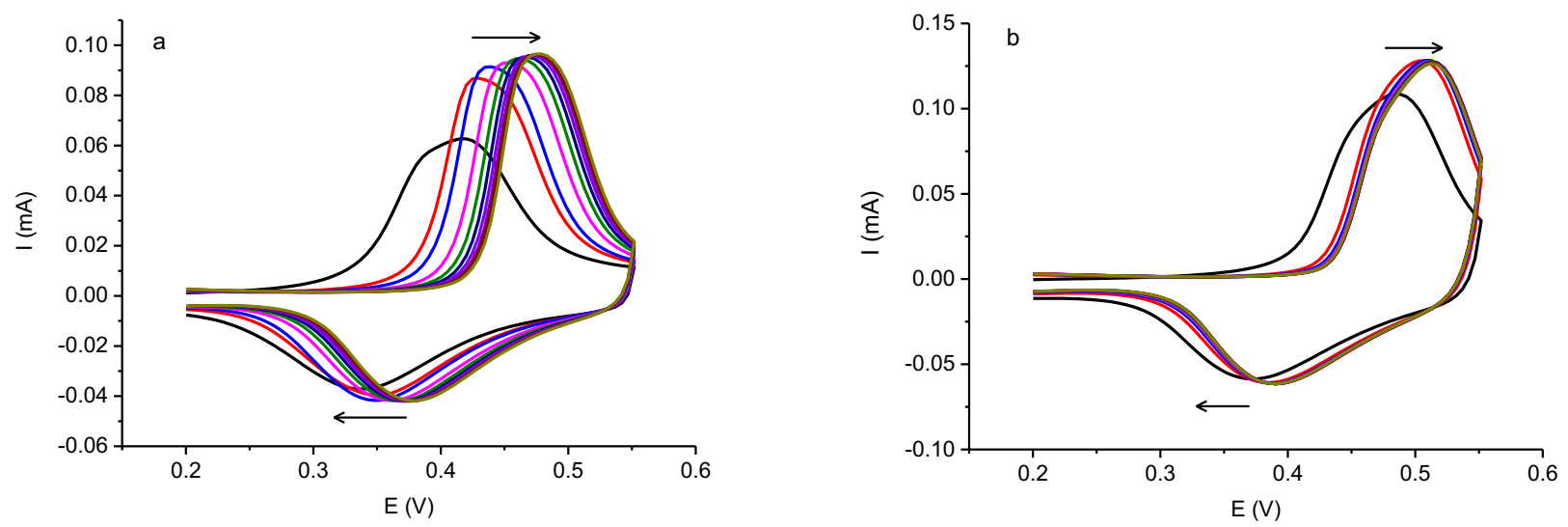

Figure 6: Voltammetric responses of (a) PANI film (from figure 4) and (b) PANI/MWCNT film (from figure 5) during redox cycling $\left(v=5 \mathrm{mV} \mathrm{s}^{-1}\right)$ in monomer-free $1 \mathrm{M} \mathrm{H}_{2} \mathrm{SO}_{4} /$ ETH200. Black curve represents first cycle; arrows indicate evolution of response with cycling. Electrode: Pt on QCM crystal. 

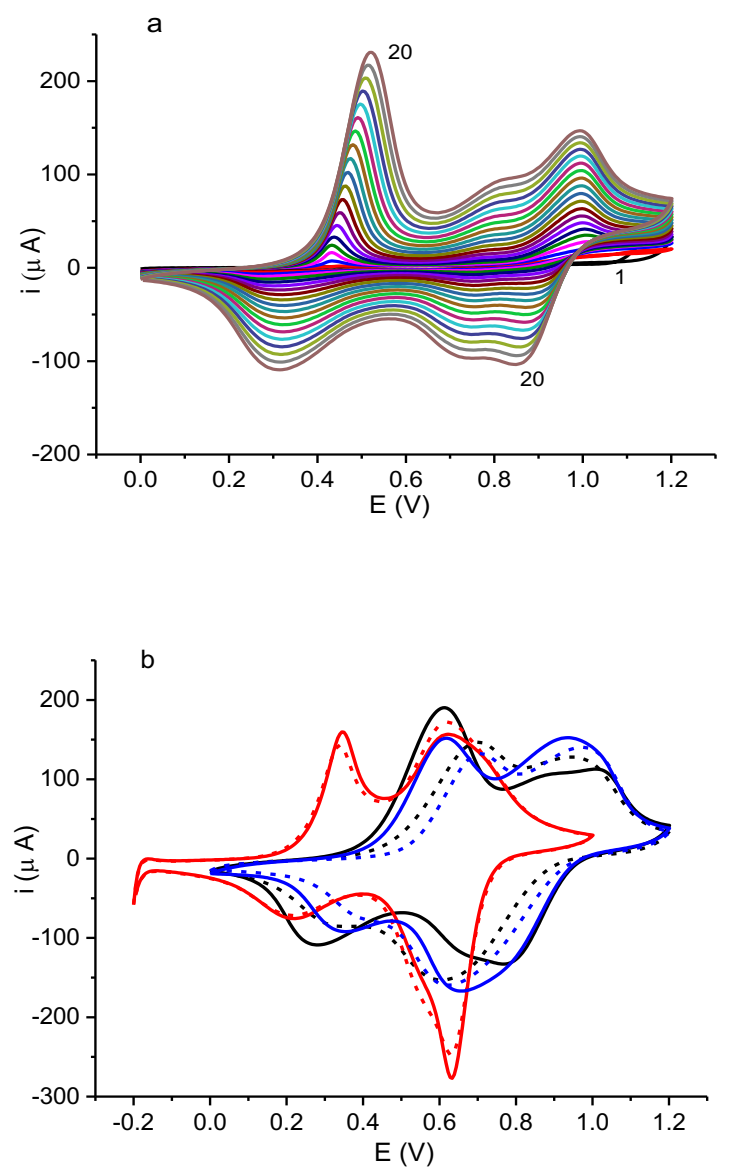

Figure 7: (a) Voltammetric responses during potentiodynamic deposition (scan rate, $v=100$ $\mathrm{mV} \mathrm{s}^{-1}$ ) of PANI from 0.8 $\mathrm{M}$ aniline / Ox: $\mathrm{ChCl}$ (Oxaline) onto a Pt electrode. (b)

Voltammetric responses for the film from (a) during redox cycling in a series of medium transfer experiments. Initial solution: Oxaline (black traces); transfer to aqueous $0.5 \mathrm{M} \mathrm{H}_{2} \mathrm{SO}_{4}$ (red traces); transfer back to Oxaline (blue traces). First cycle in each medium: full lines; $20^{\text {th }}$ cycle in each medium (dashed lines). $v=100 \mathrm{mV} \mathrm{s}^{-1}$. Electrode: Pt disc. 

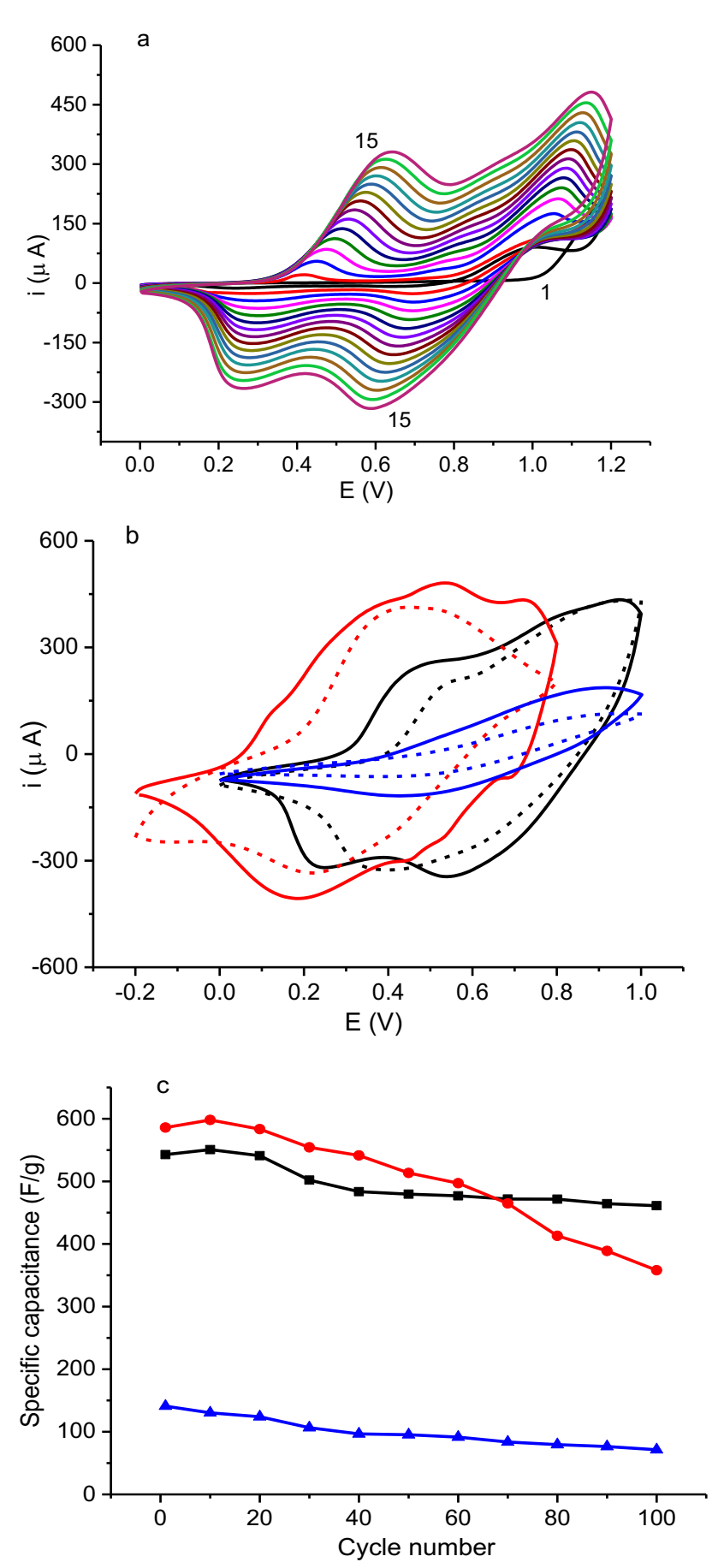
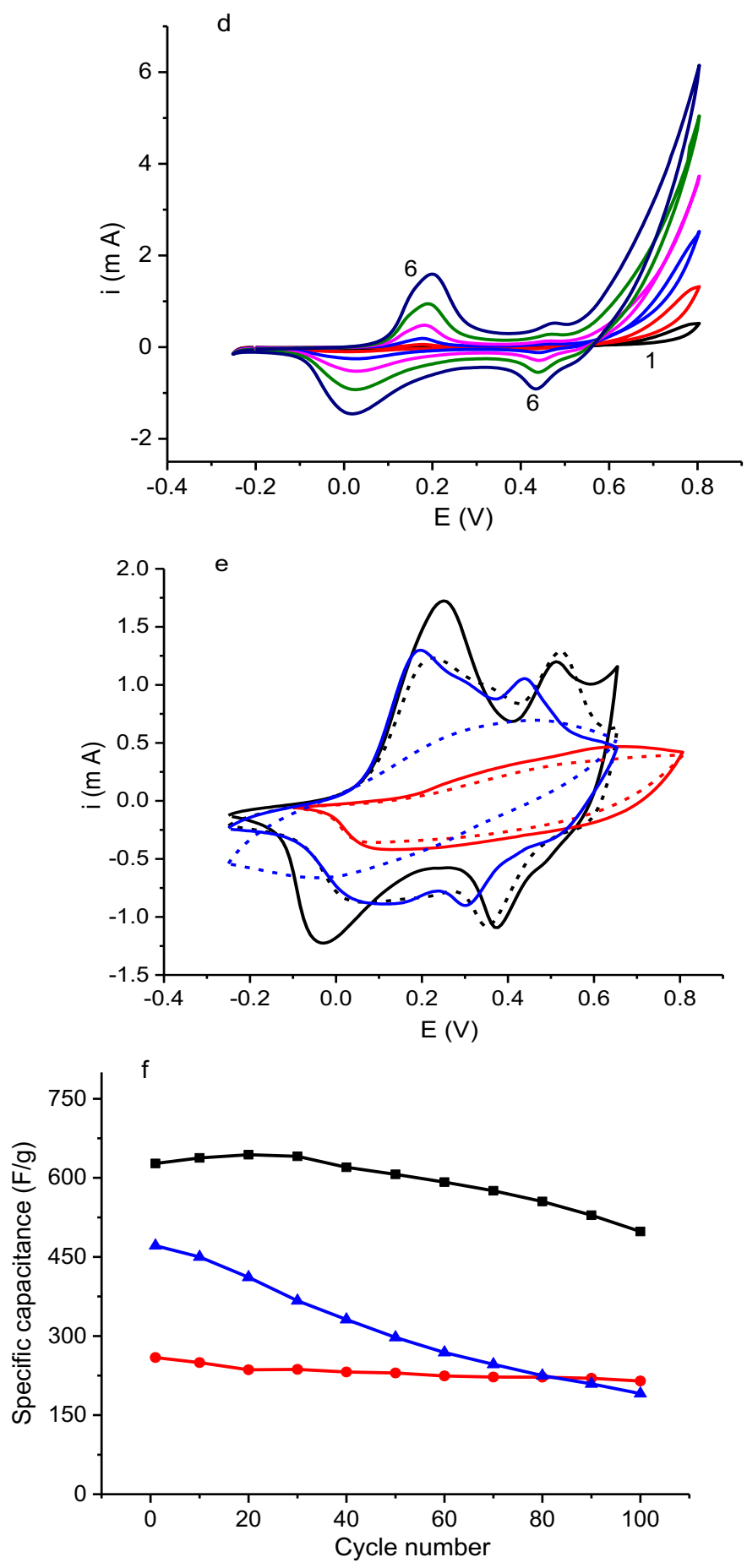

Figure 8: Electrochemical responses for mirror-image medium transfer experiments on PANI films deposited potentiodynamically on $\mathrm{Pt}$ from $0.2 \mathrm{M}$ aniline in $\mathrm{Ox}: \mathrm{ChCl}$ (panels a-c) and from $0.2 \mathrm{M}$ aniline in aqueous 1.0 $\mathrm{M} \mathrm{H}_{2} \mathrm{SO}_{4}$ (panels d-f). Panels (a) and (d) show film growth. Panels (b) and (e) show responses in background electrolytes. (b) Initial solution: $2 \mathrm{Eg}$ : $\mathrm{ChCl}$ (black traces); transfer to aqueous $0.5 \mathrm{M} \mathrm{H}_{2} \mathrm{SO}_{4}$ (red traces); transfer back to $2 \mathrm{Eg}$ : $\mathrm{ChCl}$ (blue traces). (e) Initial solution: aqueous $0.5 \mathrm{M} \mathrm{H}_{2} \mathrm{SO}_{4}$ (black traces); transfer to $2 \mathrm{Eg}$ : $\mathrm{ChCl}$ (red traces); return to aqueous $0.5 \mathrm{M}$ $\mathrm{H}_{2} \mathrm{SO}_{4}$ (blue traces). (b) and (e): First cycle in each medium: full lines; $100^{\text {th }}$ cycle in each medium (dashed lines). Panels (c) and (f) show specific capacitance values as a function of cycle number (line styles as in (b) and (e)). The potential scan rate in all cases was $5 \mathrm{mV} \mathrm{s}^{-1}$. Electrode: Pt flag. 

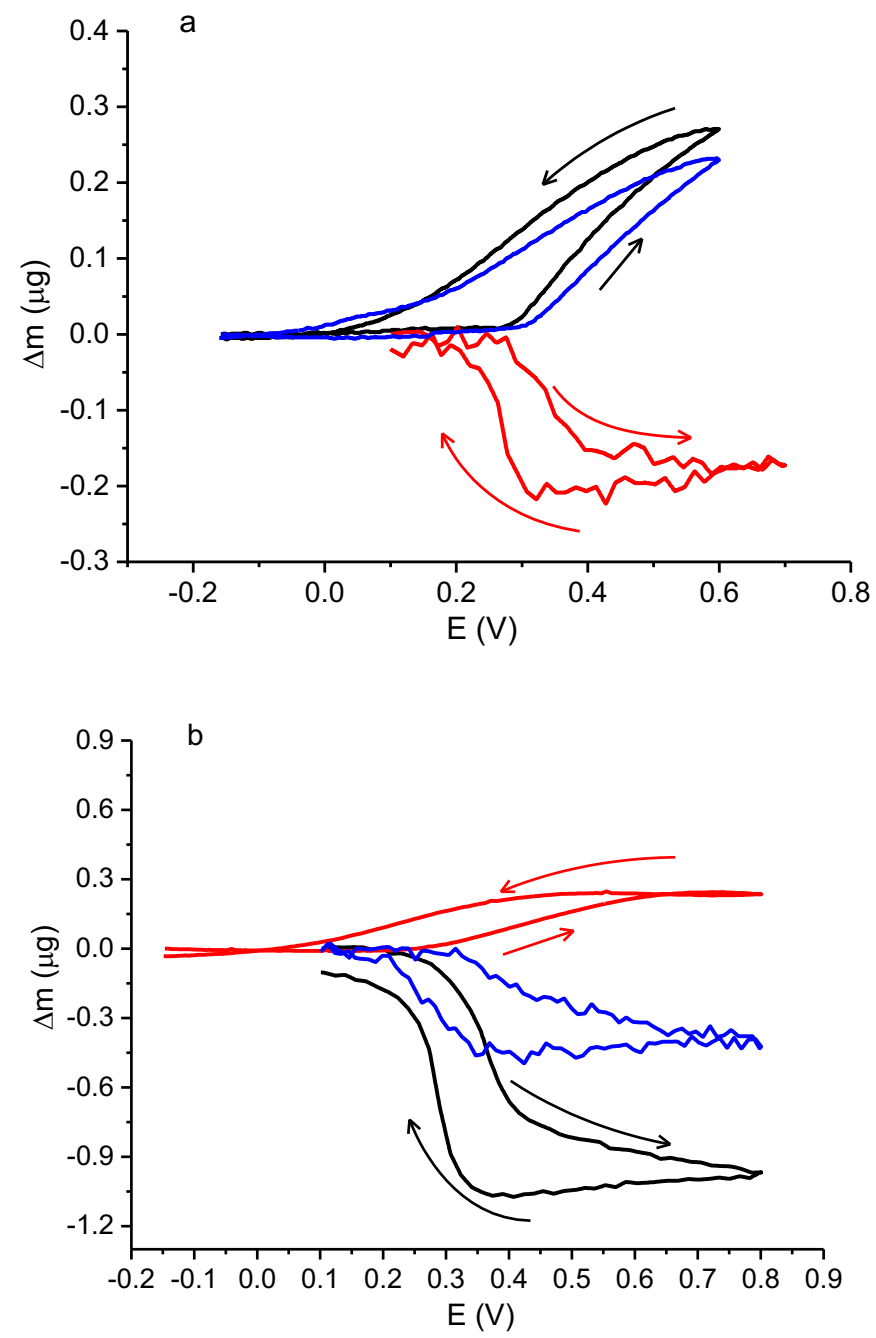

Figure 9: EQCM responses for PANI films during medium transfer experiments. Panel (a) is for a PANI film deposited from aqueous $0.5 \mathrm{M} \mathrm{H}_{2} \mathrm{SO}_{4}$, then exposed to the sequence of monomer-free electrolytes $0.5 \mathrm{M} \mathrm{H}_{2} \mathrm{SO}_{4}$, then Ethaline, then $0.5 \mathrm{M} \mathrm{H}_{2} \mathrm{SO}_{4}$ (black, red and blue traces, respectively). Panel (b) is for a PANI film deposited from Oxaline, then exposed to the sequence of monomer-free electrolytes Ethaline, then $0.5 \mathrm{M} \mathrm{H}_{2} \mathrm{SO}_{4}$, then Ethaline (black, red and blue traces, respectively). For this experiment (only) $\mathrm{T}=50{ }^{\circ} \mathrm{C}$, to expedite solution transport and equilibration. Electrode: Pt on QCM crystal. 

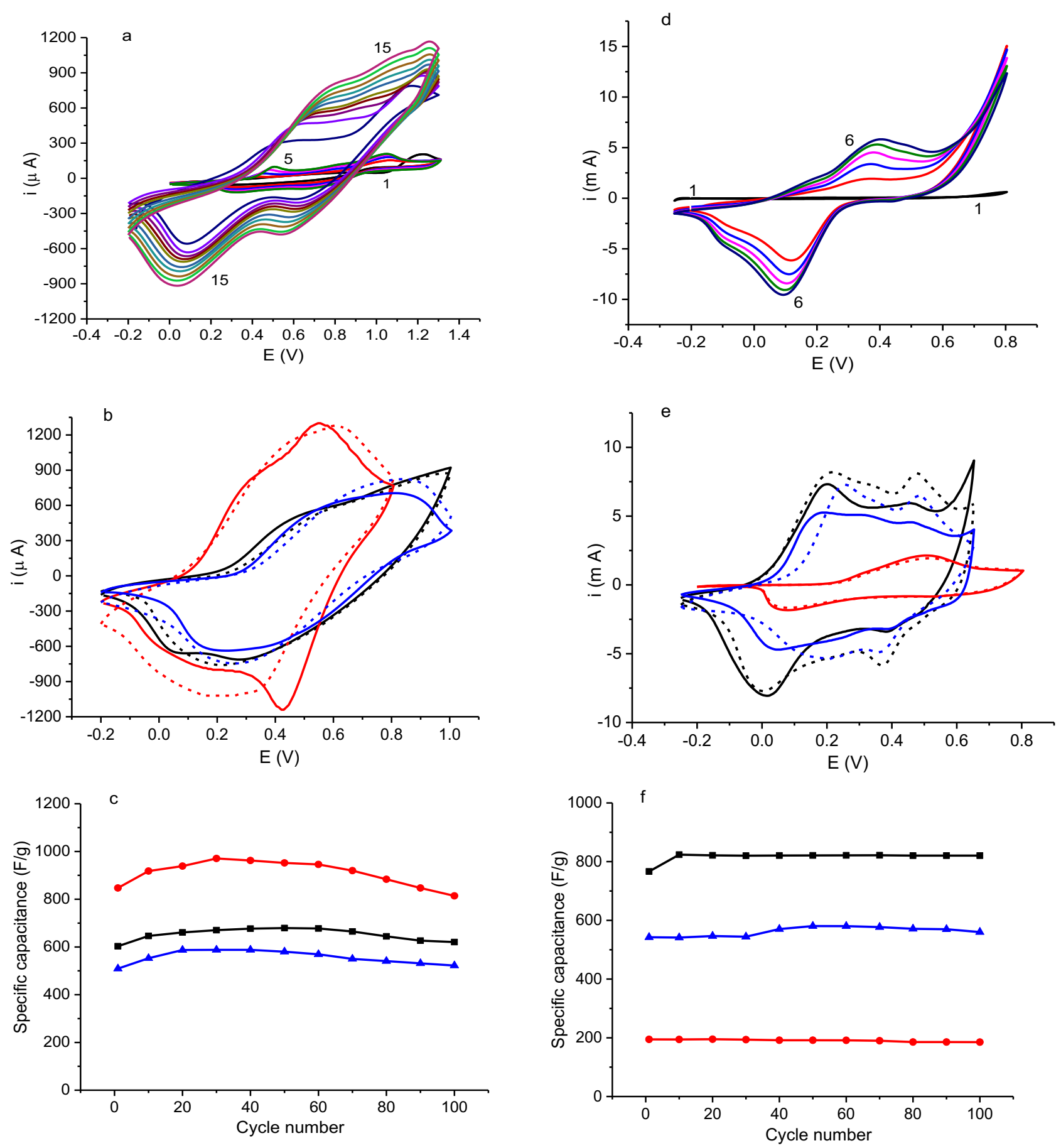

Figure 10: Electrochemical responses for mirror-image medium transfer experiments on PANI/Gr/ $/ \mathrm{MoO}_{2}$ films deposited potentiodynamically from $0.2 \mathrm{M}$ aniline in $\mathrm{Ox}$ : $\mathrm{ChCl}$ (panels ac) and from $0.2 \mathrm{M}$ aniline in aqueous $1.0 \mathrm{M} \mathrm{H}_{2} \mathrm{SO}_{4}$ (panels d-f). Panels (a) and (d) show film growth. Panels (b) and (e) show responses in background electrolytes. (b) Initial solution: 2Eg:ChCl (black traces); transfer to aqueous $0.5 \mathrm{M} \mathrm{H}_{2} \mathrm{SO}_{4}$ (red traces); transfer back to 2Eg: $\mathrm{ChCl}$ (blue traces). (e) Initial solution: aqueous $0.5 \mathrm{M} \mathrm{H}_{2} \mathrm{SO}_{4}$ (black traces); transfer to 2Eg: $\mathrm{ChCl}$ (red traces); return to aqueous $0.5 \mathrm{M} \mathrm{H}_{2} \mathrm{SO}_{4}$ (blue traces). (b) and (e): First cycle in each medium: full lines; $100^{\text {th }}$ cycle in each medium (dashed lines). Panels (c) and (f) show specific capacitance values as a function of cycle number (line styles as in (b) and (e)). The potential scan rate in all cases was $5 \mathrm{mV} \mathrm{s}^{-1}$. Electrode: Pt flag. 


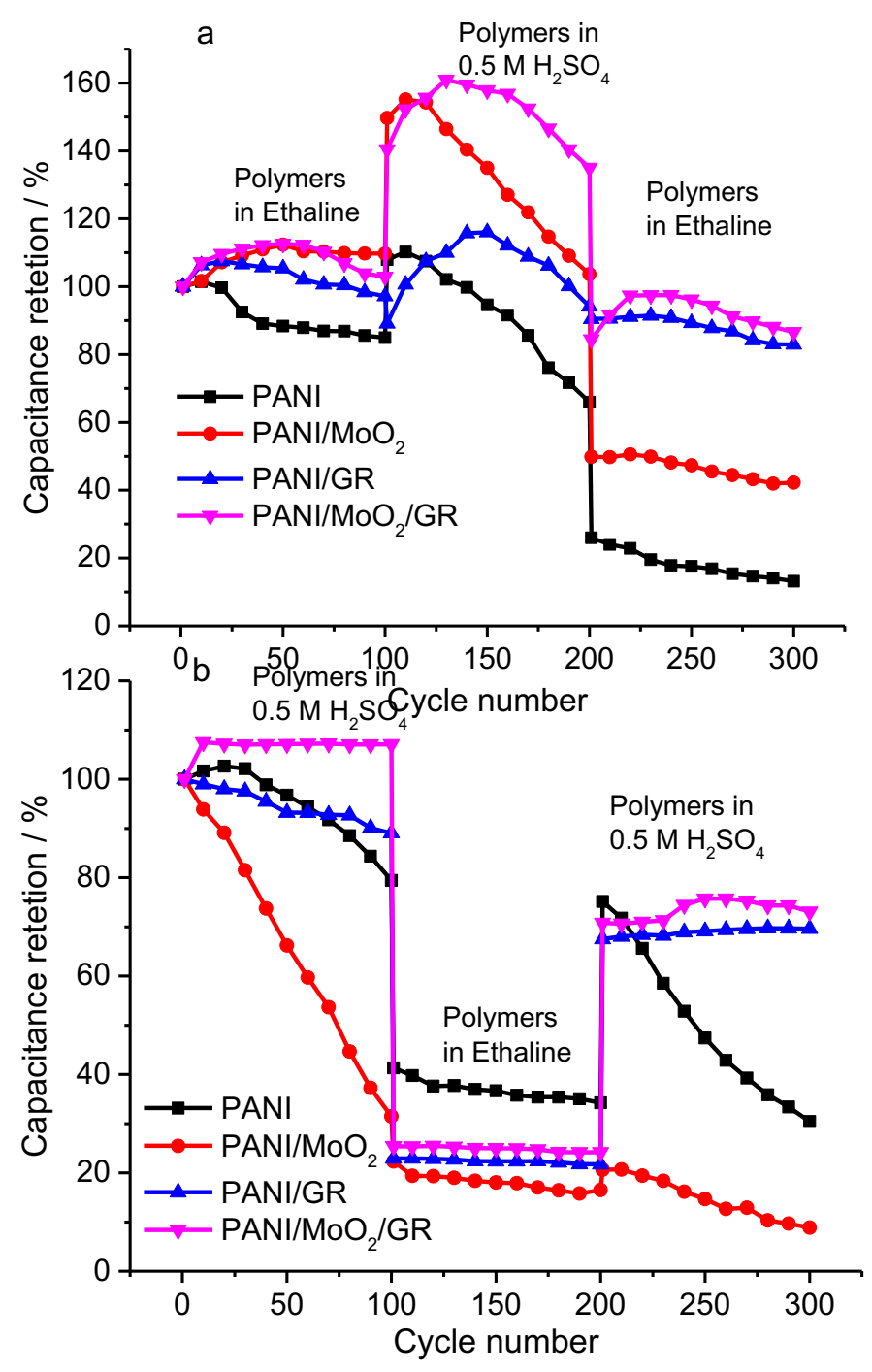

Figure 11: Summarised data for specific capacitance during redox cycling as a consequence of exchange between DES and aqueous electrolytes. (a) Films were grown from 0.2 $\mathrm{M}$ aniline / $\mathrm{Ox}: \mathrm{ChCl}$ (Oxaline) on a Pt electrode and cycled in monomer free $2 \mathrm{Eg}$ : $\mathrm{ChCl}$, then $0.5 \mathrm{M} \mathrm{H}_{2} \mathrm{SO}_{4}$ then $2 \mathrm{Eg}$ : $\mathrm{ChCl}$; (b) Films were grown from $0.2 \mathrm{M}$ aniline /aqueous $1.0 \mathrm{M} \mathrm{H}_{2} \mathrm{SO}_{4}$, cycled in monomer free $0.5 \mathrm{M} \mathrm{H}_{2} \mathrm{SO}_{4}$, then $2 \mathrm{Eg}$ : $\mathrm{ChCl}$, then $0.5 \mathrm{M} \mathrm{H}_{2} \mathrm{SO}_{4}$. Electrode: Pt flag. Data from Figures 8 and 10 and analogues (not shown) for $\mathrm{PANI} / \mathrm{Gr}$ and $\mathrm{PANI} / \mathrm{MnO}_{2}$ composite films. 


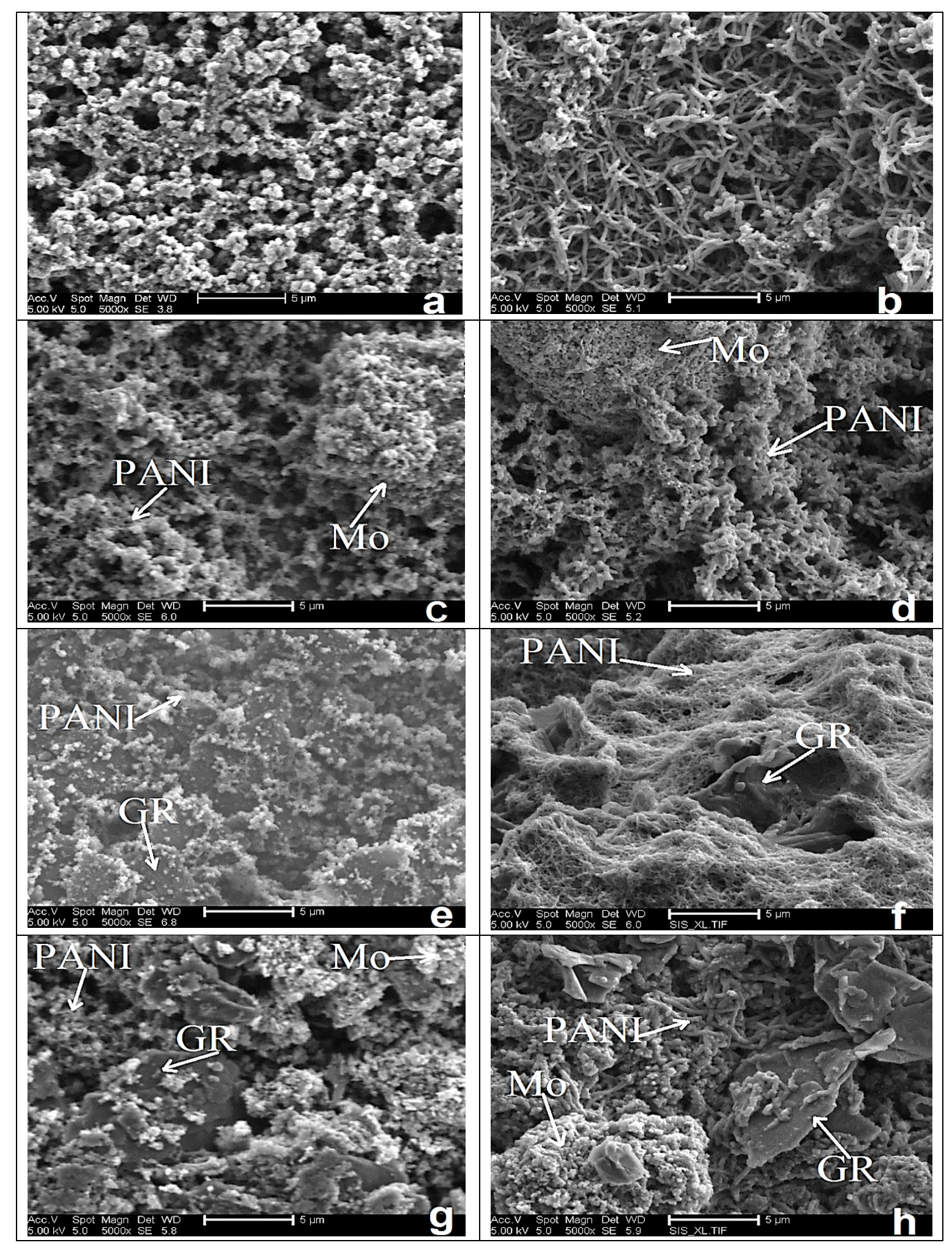

Figure 12: SEM images of (a),(b): PANI; (c), (d): PANI/MoO ${ }_{2}$; (e), (f): PANI/Gr; and (g), (h): $\mathrm{PANI} / \mathrm{MnO}_{2} / \mathrm{Gr}$ composite films before cycling in monomer-free electrolyte. Panels (a), (c), (e) and (g) show samples prepared from an Oxaline electrolyte, while panels (b), (d), (f) and (h) show samples prepared from aqueous electrolyte. 


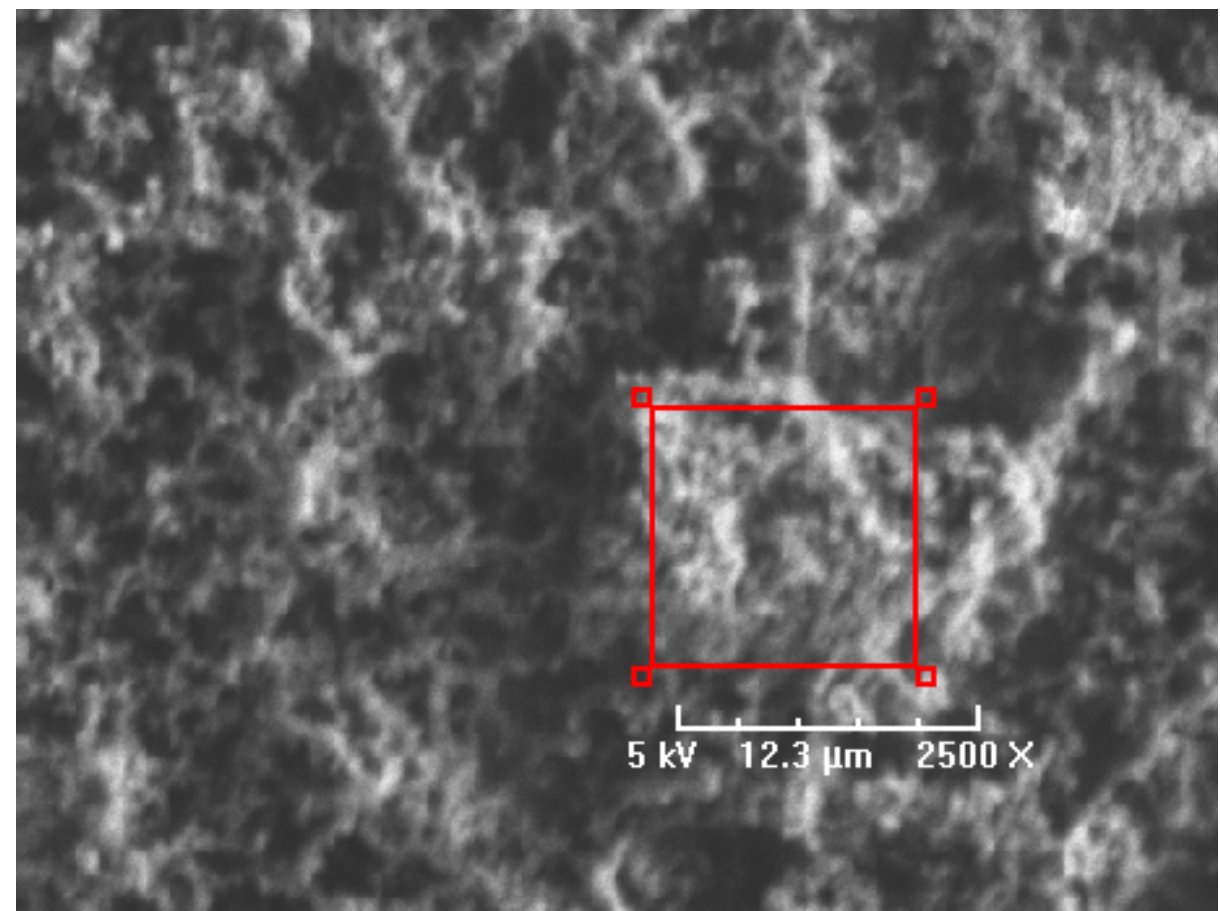

\section{Counts}

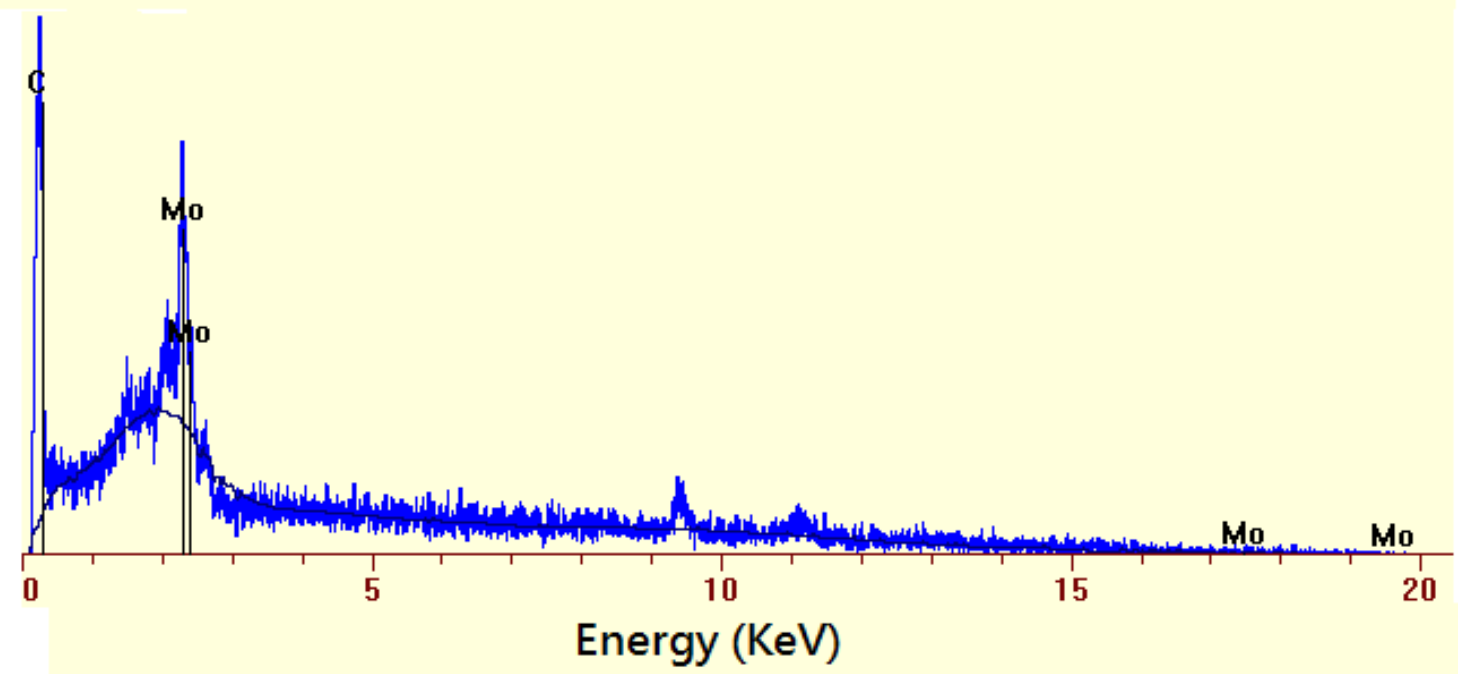

Figure 13: SEM image of PANI/MoO 2 composite film (deposited from aqueous $0.2 \mathrm{M}$ aniline / $1 \mathrm{M} \mathrm{H}_{2} \mathrm{SO}_{4}$ (procedure as in Figure 1) and EDX spectrum of sampled area within red square, indicating presence of Mo. 